\title{
Effect of shot peening on the surface properties, corrosion and wear performance of 17-4PH steel produced by DMLS additive manufacturing
}

\author{
Mariusz Walczak $^{1}$ D $\cdot$ Mirosław Szala ${ }^{1}$ D
}

Received: 21 April 2021 / Revised: 7 September 2021 / Accepted: 12 September 2021 / Published online: 24 September 2021

(c) The Author(s) 2021

\begin{abstract}
Components produced by additive manufacturing (AM) via direct metal laser sintering (DMLS) have typical as-fabricated surface defects. As a result, surface properties of AM products should be modified to increase their strength, anti-wear behaviour, and at the same time to ensure their high corrosion resistance. Surface modification via shot peening is considered suitable for additive manufacturing of medical devices made of 17-4PH stainless steel. The objective of this study was to determine the effect of shot peening pressures $(0.3 \mathrm{MPa}$ and $0.6 \mathrm{MPa})$ and three types of blasting media (CrNi steel shot, nutshell granules and ceramic beads) on the tribological characteristics and corrosion resistance of specimens of DMLS 17-4PH stainless steel. Results demonstrated that shot peening caused steel microstructure refinement and-except for the nutshell shot-peened specimens-induced both martensite $(\alpha)$ formation and retained austenite $(\gamma)$ reduction. 17-4PH specimens peened with steel and ceramic shots showed the highest increase in surface hardening by approx. 119\% (from 247 to $542 \mathrm{HV}$ ), which significantly improved their wear resistance. The highest mechanical properties (hardness and wear resistance) and corrosion resistance were obtained for the surfaces modified using the following media: ceramic beads $>\mathrm{CrNi}$ steel shot $>$ nutshell granules. Adhesive and fatigue wear were two predominant mechanisms of tribological deterioration. Results demonstrated that the application of shot peening using ceramic beads led to grain size refinement from 22.0 to $14.6 \mathrm{~nm}$ and surface roughness reduction, which in turn resulted in higher corrosion resistance of the material. DMLS $17-4 \mathrm{PH}$ specimens modified by shot peening using ceramic beads and a pressure of $0.6 \mathrm{MPa}$ exhibited the optimum surface morphology, hardness and microstructure, and thus improved wear and corrosion performance.
\end{abstract}

Keywords Shot peening $\cdot 17-4 \mathrm{PH}$ steel $\cdot$ Corrosion $\cdot$ Wear $\cdot$ Surface engineering $\cdot$ Additive manufacturing $\cdot$ Tribology

\section{Introduction}

17-4PH (1.4542, $\mathrm{X} 5 \mathrm{CrNiCuNb} 16-4)$ is precipitation-hardened martensitic stainless steel, strengthened with finedispersion precipitates of intermetallic phases [1]. Due to its high mechanical properties and corrosion resistance, this steel grade is used for construction and related applications in marine environments, power plants (light and

Mirosław Szala

m.szala@pollub.pl

Mariusz Walczak

m.walczak@pollub.pl

1 Department of Materials Engineering, Faculty of Mechanical Engineering, Lublin University of Technology,

Nadbystrzycka 36, 20-618 Lublin, Poland pressurized-water reactors), chemical industry and medical devices [2]. Owing to its high mechanical properties, this material is also suitable for short production runs, as well as for prototyping machine parts requiring high resistance to corrosion and wear. In recent years one can observe a growing interest in additive manufacturing (AM) components made of austenitic [3] and martensitic [4] stainless steels, as well as high-strength [5] and other steels [6]. Numerous studies have shown that in spite of applying optimum printing parameters recommended by manufacturers of direct metal laser sintering systems, 3D-printed products exhibit typical surface defects and discontinuities. Specifically, the surface of 3D-printed components may contain unmelted metal powder particles or have pores formed due to weld pool collapse. Such defects may reduce product functional parameters. It is clear that most deterioration processes occurring in machine parts and components, such as stress 
crack formation and sliding or corrosion wear, are initiated at the surface and result from surface non-uniformities. Moreover, laser sintering of metal powders induces residual stresses in products [7]. From a wide range of industrial surfacing processes for improving the operation time of metallic structures, such as a combination of hardfacing and nitriding [8], surfacing via cold spraying [9] and thermal deposition of hard ceramics [10], it is recommended that DMLS systems (additive manufactured metallic components) should be modified via shot peening to improve the properties of 3D-printed machine parts. Furthermore, according to Benedetti et al. [11], the use of shot peening induces advantageous compressive stresses and reduces surface layer porosity, which - in turn - leads to increased fatigue strength.

According to the literature $[12,13]$, the shot peening process causes shot particles to penetrate the surface of a given material, thus changing the tribological characteristics and corrosion resistance of products modified in this way. Kameyama and Komotori [14] proposed a model describing both the transfer and mechanical mixing of shot medium particles on the surface of material. According to these authors, the use of shot peening leads to the formation of a local lamellar microstructure. The surface of material is changed in such a way that the shot particles impacting the material can break its continuity and cause it to spall, while at the same time the shot particles break off and remain on the surface. With every successive blast, the shot particles are "pressed" into the surface of the material more deeply, causing local hardening of the material and creating a characteristic lamellar structure with its properties differing from those of the material core.

Surface properties are of key importance for the functional properties of additive manufactured parts. There are many studies investigating the problem of selecting appropriate shot type and shot peening parameters such as blasting pressure to obtain the required surface properties, mechanical and wear behaviour [15], and corrosion resistance [16]. Given a wide range of available shot materials (i.e. blasting media) with different morphologies and particle size (granulation), the selection of a suitable shot type also seems to be a complex problem.

17-4PH stainless steel parts produced by conventional methods are characterized by high resistance to wear and corrosion. Nevertheless, there exist very few studies investigating the relationship between shot peening parameters and the surface properties and wear resistance of 3D-printed 17-4PH steel products. The surface morphology of 3D-printed materials is characterized by inhomogeneity, and its properties are typical of cast metal alloys. One of the methods for modifying surface properties of 3D-printed metallic materials is shot peening. For the modification of steel products fabricated by additive manufacturing, the selection of an appropriate peening pressure is of considerable importance to the final effect because it ensures, among other things, high corrosion and wear resistance of the product. Nonetheless, there exist very few studies offering a comprehensive analysis of the effect of peening pressure and different types of blasting shot (ceramic, organic or steel particles) on the corrosion and wear performance of additive manufactured 17-4PH. The selection of suitable shot peening parameters is therefore a research problem that needs to be investigated. Moreover, the literature review shows that no study to date has synthesized the effects of shot type (ceramic, organic or steel particles) and peening pressure on the surface roughness, microstructural phase development, hardness, wear and corrosion behaviour of additive manufactured $17-4 \mathrm{PH}$ steel. To fill this literature gap, the present study will investigate the above problem.

The aim of this study is, therefore, to investigate the effect of shot peening parameters (blasting shot type and high/low peening pressure) on the corrosion and wear resistance of 17-4PH stainless steel manufactured by direct metal laser sintering (DMLS).

\section{Experimental procedure}

\subsection{Specimen preparation and post-sintering treatment}

Specimens of EOS Stainless Steel GP1 feedstock powder (EOS GmbH, Germany) were fabricated by direct metal laser sintering (DMLS). The nominal chemical composition of this stainless steel powder is similar to that of 17-4PH (AISI) and 1.4542 (EN) stainless steels. Disc-shaped specimens with a diameter of $30 \mathrm{~mm}$ and a height of $6 \mathrm{~mm}$ (Fig. 1) were printed by DMLS using EOSINT M280 (EOS $\mathrm{GmbH}$, Germany). The manufacturing process was performed in a nitrogen atmosphere, in compliance with the

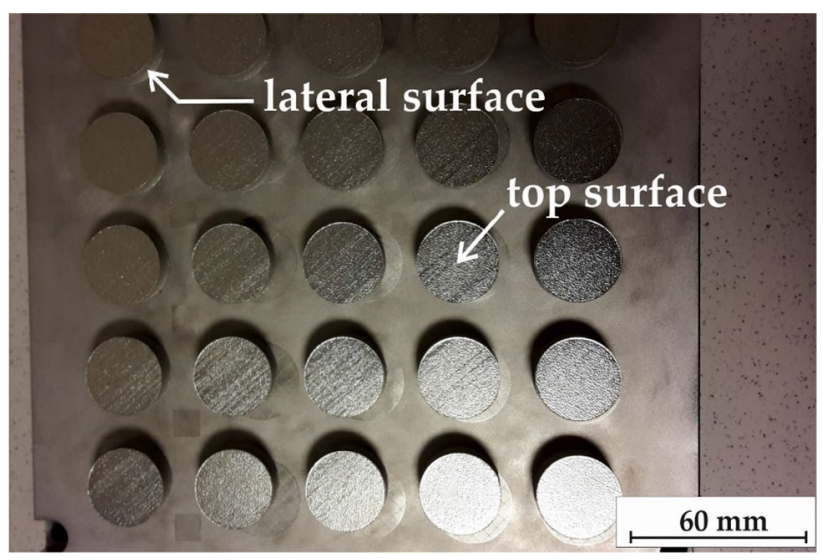

Fig. 1 Disc specimens of as-fabricated $17-4 \mathrm{PH}$, with the dimensions of $\emptyset 30 \times 6 \mathrm{~mm}$ 
optimal additive manufacturing process parameters recommended by the EOS manufacturer, the most important of these parameters being: laser power $200 \mathrm{~W}$, layer thickness $0.02 \mathrm{~mm}$, scan speed $1000 \mathrm{~mm} / \mathrm{s}$, and laser spot size $0.1 \mathrm{~mm}$.

Top surfaces of the specimen face in the $X-Y$ horizontal plane (see Fig. 1) were subjected to shot peening with Peenmatic micro 750S (IEPCO, Switzerland), using three different media: $\mathrm{CrNi}$ steel shot, nutshell granules and ceramic beads. Also, two different peening pressures were applied: $0.3 \mathrm{MPa}$ and $0.6 \mathrm{MPa}$ (Table 1). This was essential for the determination of the effect of low and high peening pressures on both the corrosion and wear behaviour of additive manufactured 17-4PH steel. Moreover, the usage of an extensive range of material types (ceramic, organic or steel particles), with different morphologies of the blasting media, helped determine their influence on the operating properties of shot-peened additive manufactured surfaces. Two parameters were maintained constant in the tests: the peening time (60 s) and the distance between the nozzle and the end face

Table 1 Notations of specimens subjected to different surface processing via shot peening

\begin{tabular}{llc}
\hline $\begin{array}{l}\text { Specimen nota- } \\
\text { tion }\end{array}$ & Shot type & $\begin{array}{l}\text { Peening } \\
\text { pressure } \\
\text { (MPa) }\end{array}$ \\
\hline S3 & Stainless steel & 0.3 \\
S6 & Stainless steel & 0.6 \\
N3 & Nutshell granules & 0.3 \\
N6 & Nutshell granules & 0.6 \\
C3 & Ceramic beads & 0.3 \\
C6 & Ceramic beads & 0.6 \\
Ref. & Unmodified, as-fabricated DMLS & $17-4 \mathrm{PH}$ \\
& (reference) \\
\hline
\end{tabular}

of the shot-peened surface $(20 \mathrm{~mm})$. In all experiments, the shot peening process was performed perpendicularly to the surface. The selection of shot types and peening parameters was done based on our previous studies investigating the properties of additive manufactured Ti-6Al-4 V alloy, namely-tribological behaviour [17], corrosion resistance [18], mechanical properties and cytotoxicity [19]. The results of those studies served as a basis for the selection of shot peening parameters for additive manufactured 17-4PH specimens. Furthermore, similarly to the investigated Ti6Al-4 V alloy, the 17-4PH grade steel is considered suitable for manufacturing medical devices; due to this fact, both the corrosion and wear behaviour of 17-4PH was investigated under comparable shot peening conditions.

Specimen notations used throughout this paper are listed in Table 1. The characteristics of blasting media used in the peening process are given in Table 2. Shot morphologies were examined with a scanning electron microscope (SEM, Phenom ProX Phenom-World, Waltham, MA, USA), and captured images are given in Fig. 2. In this study, asfabricated (unpeened) DMLS specimens were used as the reference (they are marked as Ref.).

\subsection{Powder characterization}

The scanning electron microscopy (SEM) examination of the commercial powder GP1 confirmed that the feedstock was a mixture of particles of rounded and irregular shapes; the particles were elongated and had satellite particles attached to their surfaces, see Fig. 3. On average, the gas-atomized powder was $15-45 \mu \mathrm{m}$ in diameter.

Chemical composition analysis was performed with a Magellan Q8 spark emission spectrometer (Bruker, Germany) using the Fe130 software. Five analyses (sparks) were

Table 2 Characteristics of shots used for shot peening, according to the manufacturer's data (Kuhmichel Abrasiv GmbH)

\begin{tabular}{|c|c|c|c|c|c|}
\hline Shot type & \multicolumn{2}{|c|}{ Nominal chemical composition (\%) } & $\begin{array}{l}\text { Average grain size } \\
(\mu \mathrm{m})\end{array}$ & Grain shape & Hardness \\
\hline Stainless steel shot $-\mathrm{CrNi}$ & $\begin{array}{l}\mathrm{Cr} \\
\mathrm{Ni} \\
\mathrm{Si} \\
\mathrm{Mn} \\
\mathrm{C} \\
\mathrm{Fe}\end{array}$ & $\begin{array}{l}16-20 \\
7-9 \\
1.8-2.2 \\
0.7-1.2 \\
0.05-0.2 \\
\text { Bal }\end{array}$ & $400-900$ & Spherical & $\begin{array}{l}235 \mathrm{HV} \text { (equivalent } \\
\text { of approx. 3.5-3.6 } \\
\text { Mohs) }\end{array}$ \\
\hline $\begin{array}{l}\text { Nutshell granules } \\
\text { Ceramic beads }\end{array}$ & $\begin{array}{l}\text { Non-m } \\
\mathrm{ZrO}_{2} \\
\mathrm{SiO}_{2} \\
\mathrm{Al}_{2} \mathrm{O}_{3} \\
\mathrm{CaO} \\
\mathrm{TiO}_{2} \\
\mathrm{Fe}_{2} \mathrm{O}_{3}\end{array}$ & $\begin{array}{l}\text { ting media } \\
61.98 \\
27.77 \\
4.57 \\
3.47 \\
0.34 \\
0.14\end{array}$ & $\begin{array}{l}450-800 \\
125-250\end{array}$ & $\begin{array}{l}\text { Angular } \\
\text { Spherical }\end{array}$ & $\begin{array}{l}\text { Approx. 2.5-3.5 Mohs } \\
\text { Approx. 7-7.5 Mohs }\end{array}$ \\
\hline
\end{tabular}




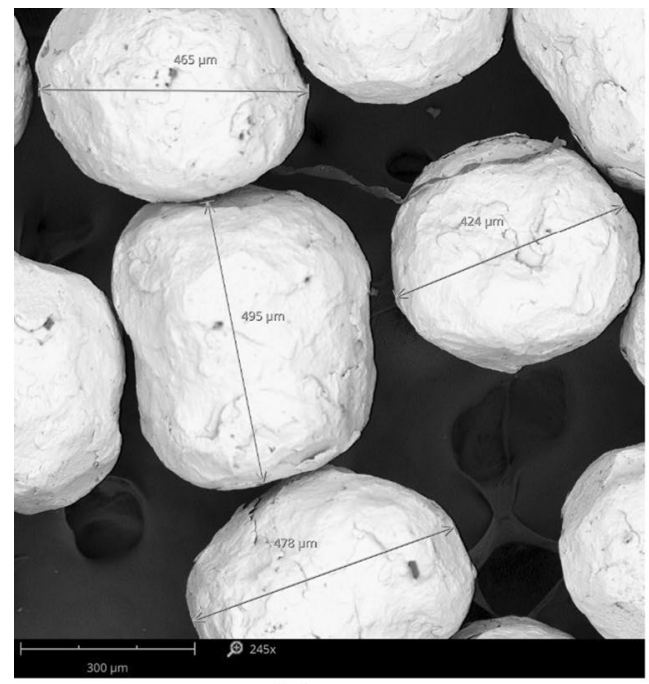

(a)

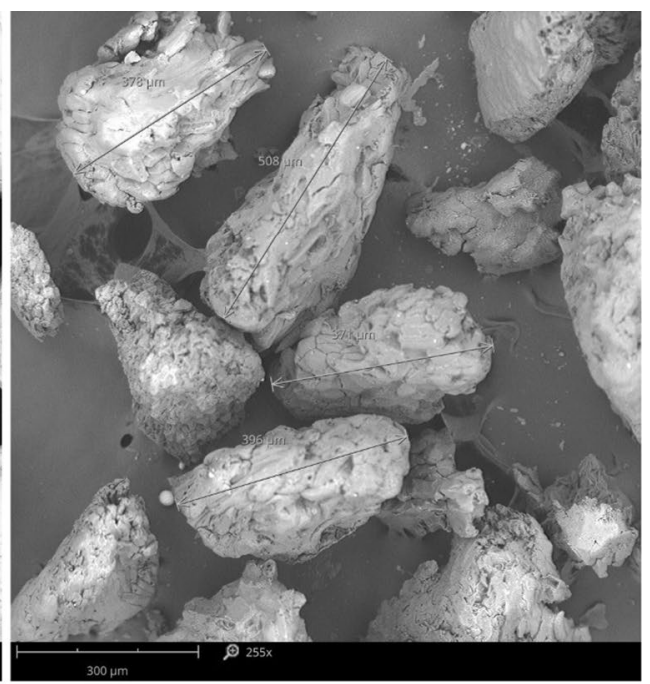

(b)

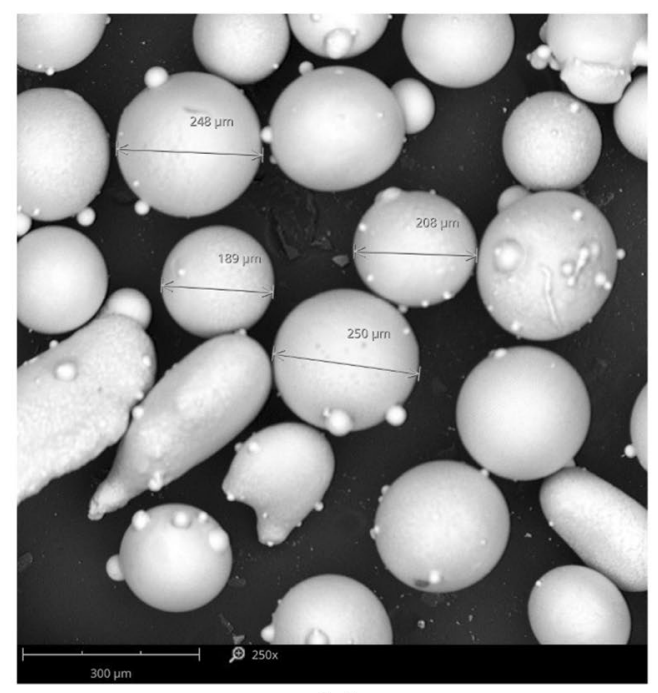

(c)

Fig. 2 Comparison of different shot types used in the study: a CrNi steel, $\mathbf{b}$ nutshell granules and $\mathbf{c}$ ceramic beads, SEM

made per every specimen. The objective of the analysis was to verify whether the actual chemical composition of the studied steel grade complied both with the data provided by the manufacturer in the operation sheets and with the requirements of the ASTM A564 standard. It was found that the chemical composition of the analysed steel grade complied with the requirements for 17-4PH steel under the ASTM A564 standard, as proven by data given in Table 3.

\subsection{Characteristics of shot-peened steel specimens}

Surface roughness of the shot-peened specimens was evaluated using a Dektak 150 contact profilometer (Veeco Instruments, USA). Measurements were made using the stylus with a rounding radius of $2 \mu \mathrm{m}$ over a measuring length of $5 \mathrm{~mm}$ and under a load of $3 \mathrm{mg}$. The measurements were made for every specimen in 16 randomly selected locations. To include the effect of texture, a total of 16 measurements were made: 8 alongside and 8 perpendicular to the laser beam scanning direction. After that, the average value was calculated. To compare different DMLS specimens, the average surface roughness was calculated from the arithmetic average roughness $R_{a}$ according to the ISO 4287 standard. Changes in the surface morphology of shot-peened specimens were examined by SEM with magnification ranging from $500 \times$ to $1500 \times$, using a backscatter electron detector (BSD) and topographic analysis mode.

The phase composition of both unpeened and shot-peened specimens, as well as their grain size development caused by different peening parameters, were investigated using a high-resolution X-ray diffractometer (XRD, Empyrean, Panalytical) with $\mathrm{Cu} \mathrm{K}-\alpha$ radiation and $\mathrm{Ni}$-filter with a generator 


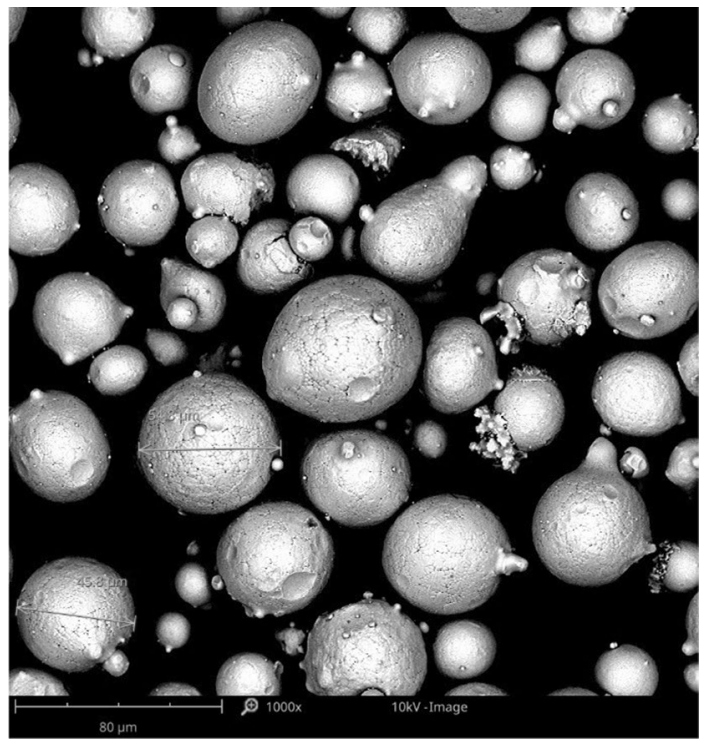

Fig. 3 Morphology of gas-atomized powder, SEM

voltage of $40 \mathrm{kV}$ and a current of $30 \mathrm{~mA}$. A proportional detector was used for detecting radiation. The specimens were measured in the Bragg-Brentano geometry over a range from $30^{\circ}$ to $100^{\circ}$. All measurements were carried out at room temperature with a step size of $0.01^{\circ}$ and a counting time of $6 \mathrm{~s}$ per data point. Specimen phase and lattice parameters from d-spacing were determined with the use of the High Score Plus software package (Panalytical).

Microhardness was measured on the top surface of the specimens using a Vickers FM-700 microhardness tester provided with the automatic system ARS 900 (Future-Tech Corp., Japan). The load used in hardness testing was $200 \mathrm{~g}$ (HV0.2) with a dwell time of $15 \mathrm{~s}$. In total, 30 indentations were made per every batch of the specimens. Moreover, mechanical testing, roughness and microscopic investigations were preceded by the ultrasonic cleaning and compressed-air drying of the prepared specimens.

\subsection{Friction and wear testing}

The coefficient of friction (COF) and wear rate were estimated with the use of a ball-on-disc tribotester (CSM Instruments, Switzerland) under technically dry friction conditions, at a room temperature of $22{ }^{\circ} \mathrm{C}$. In the test, $6 \mathrm{~mm}$ diameter calibrated balls made of tungsten carbide-cobalt (WC-Co) cemented carbide were used. The test was performed under a load of $10 \mathrm{~N}$ with a linear velocity of $0.1 \mathrm{~m} / \mathrm{s}$ over a radius of $3 \mathrm{~mm}$. Sliding wear conditions were selected to ensure solid contact between the tested surface and the countersample. COF variations were measured over a total test distance of $200 \mathrm{~m}$. Towards the end of the tribological test, the so-called wear factor $K$ (wear rate) was calculated by taking into account wear volume together with applied force and sliding distance (1):

$$
K=\frac{\text { Wear volume }}{\text { Applied force } \times \text { sliding distance }}\left[\mathrm{mm}^{3} \mathrm{~N}^{-1} \mathrm{~m}^{-1}\right]
$$

Wear volume was calculated via profilometry measurements of the worn surface, i.e. wear grooves, using a Dektak 150 contact profilometer (Veeco Instruments, USA). The tip radius of the stylus was $2 \mu \mathrm{m}$. Figure 4 shows the typical wear profile area obtained by contact profilometry, with the fitted line showing the wear groove. After that, plots were created to calculate the cross-sectional area of wear. Twelve profiles were run on the circumference of each wear trace to obtain statistics repeatability. Results of the cross-sectional area for each scan were averaged, and wear volume was evaluated by multiplying the average cross-sectional area and circumference of the wear trace. Finally, the wear mechanism was investigated using a scanning electron microscope (SEM, Phenom ProX, Phenom World, Waltham, MA, USA) equipped with an energy dispersive X-ray analyser (EDS).

\subsection{Corrosion testing}

The resistance to corrosion of the analysed specimens was determined via accelerated electrochemical corrosion testing conducted in $0.9 \% \mathrm{NaCl}$ solution at a room temperature of $22{ }^{\circ} \mathrm{C}$, using Atlas 0531 . The corroding medium (standard saline solution used for corrosion testing of medical devices [20]) was selected owing to the fact that additive manufactured $17-4 \mathrm{PH}$ is considered suitable for the production of medical products, among others. Corrosion tests were performed in a three-electrode electrochemical cell, with a platinum control electrode and a saturated calomel electrode (SCE) as the reference electrode. The each specimen
Table 3 Chemical composition analysis results

\begin{tabular}{lrllllllllll}
\hline Specimen & \multicolumn{1}{l}{ Chemical composition, wt.\% } & & & & & \\
\cline { 2 - 10 } & $\mathrm{C}$ & & $\mathrm{Si}$ & $\mathrm{Mn}$ & $\mathrm{Cr}$ & $\mathrm{Mo}$ & $\mathrm{Ni}$ & $\mathrm{Cu}$ & $\mathrm{Nb}$ & $\mathrm{Fe}$ \\
\hline 17-4 PH as-fabricated* & 0.04 & 0.71 & 0.67 & 15.85 & 0.124 .92 & 4.79 & 0.27 & $\mathrm{Bal}$ \\
EOS GmbH, metal powder & 0.01 & 0.7 & 0.7 & 15.8 & 0.4 & 4.02 & 3.9 & 0.29 & $\mathrm{Bal}$ \\
ASTM A564 & $<0.07$ & $<1$ & $<1$ & $15-17.5$ & $<0.5$ & $3-5$ & $3-5$ & $0.15-0.45$ & $70.1-78.8$ \\
\hline
\end{tabular}

*Spectrometry analysis results 
Fig. 4 Typical wear groove profile obtained in ball-on-disc testing (specimen N3)

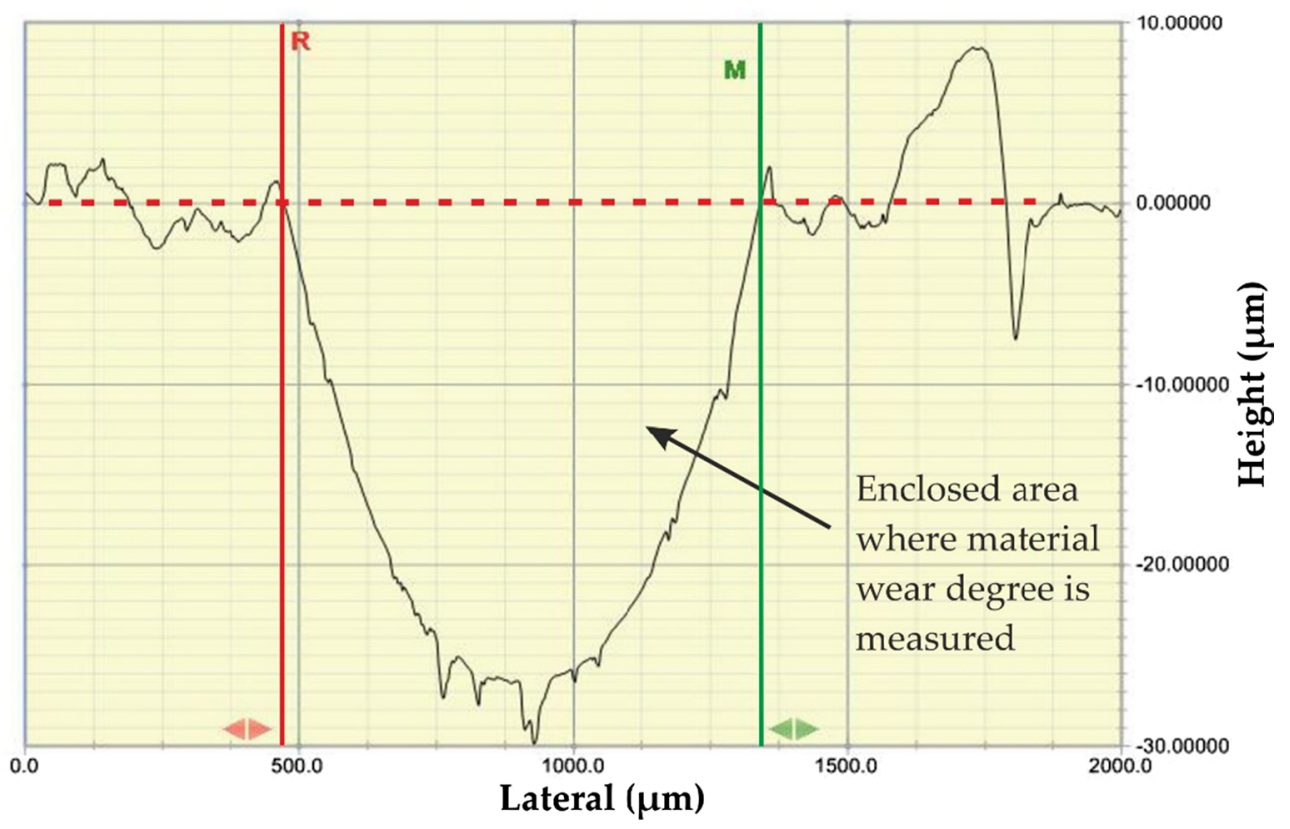

corroded area was $0.5 \mathrm{~cm}^{2}$. Three specimens were prepared for each series. Polarization curves were recorded with an automatic potential shift of $1 \mathrm{mV} / \mathrm{s}$ in the range from -500 to $+1200 \mathrm{mV}$. The corrosion rate of $1 \mathrm{mV} / \mathrm{s}$ is a typical value used in accelerated corrosion testing [20], but the range was extended because-according to the authors' previous study [18]—peened surfaces could exhibit passivation even after approx. $+600 \mathrm{mV}$. The corrosion current $i_{\text {corr }}$ and the potential $E_{\text {corr }}$ were calculated from the Tafel polarization curves via potentiodynamic analysis using AtlasLab. Using computer image analysis, the corroded areas were evaluated quantitatively by measuring ferret diameters and calculating the percentage rate of pitting. Moreover, the corroded areas were scanned and examined by optical profilometry (Contour GT, Bruker, Germany). In the analysis, a surface area of $5 \mathrm{~mm} \times 5 \mathrm{~mm}$ was examined by vertical scanning interferometry (VSI), and obtained signals were converted using the Bruker Vision 64 software. The arithmetic average of surface roughness, $S_{\mathrm{a}}$, was calculated in compliance with the ISO 25178 standard.

\section{Results and discussion}

\subsection{Surface characteristics}

The texture of machined surfaces was evaluated via the roughness parameter $R_{\mathrm{a}}$. According to a study by Ganesh et at. [21], this parameter is considered to be the most representative for shot-peened surfaces. Table 4 lists the average surface roughness $\left(R_{\mathrm{a}}\right)$ of the specimens before and after shot peening. The results demonstrate that the use of steel shot and nutshell granules leads to increased surface roughness for both tested peening pressures. The sharp-edged nutshell granules also cause the most considerable changes in the roughness profile. In contrast, the surfaces peened with ceramic beads exhibit reduced roughness. It should be stressed that the reduced degree of surface development for these specimens was obtained using two- to three-fold smaller shot when compared to the specimens peened with steel shot and nutshell granules. Moreover, an increase in peening pressure affects surface finish when the peening process is conducted using ceramic beads. The use of the smaller size shot resulted in the formation of smaller cavities on the shot-peened surface, which - with an increase in pressure-led to a bigger number of blasts per surface unit. In addition to that, for the surfaces modified by the near-spherical shot, the peening pressure increase from 0.3 to $0.6 \mathrm{MPa}$ did
Table 4 Arithmetic average roughness $R_{\mathrm{a}}$ of DMLS specimens before and after shot peening

\begin{tabular}{llllllll}
\hline Specimen & Ref. & S3 & S6 & N3 & N6 & C3 & C6 \\
\hline$R_{\mathrm{a}}(\mu \mathrm{m})$ & 5.05 & 5.79 & 5.97 & 6.48 & 7.21 & 4.67 & 4.28 \\
Standard deviation & 1.02 & 1.71 & 1.55 & 2.55 & 1.29 & 1.11 & 1.16 \\
\hline
\end{tabular}


not cause any significant differences in the $\mathrm{R}_{\mathrm{a}}$ parameter. The observed differences amount to $3.1 \%$ for the surfaces peened with steel shot and to $8.3 \%$ for the surfaces modified using ceramic beads. The type, size and geometry of shot are among the key factors affecting surface development. Oblata and Sudo [22] showed that the use of a bigger size shot causes a proportional increase in surface roughness. Dorr et al. [23] observed that for the shot size ranging 300-600 $\mu \mathrm{m}$, the use of a bigger size medium results in increased surface roughness. In contrast, the use of an $800 \mu \mathrm{m}$ diameter shot results in reduced surface roughness.

The mean diameter of steel shot and nutshell granules, as declared by the manufacturer (Kuhmichel Abrasiv $\mathrm{GmbH}$ ), was 400-900 $\mu \mathrm{m}$ and $450-800 \mu \mathrm{m}$, respectively; however, the measured values of the shot ranged 400-500 $\mu \mathrm{m}$ (see Fig. 2). Aymen et al. [24] used the shot with diameters ranging $125-450 \mu \mathrm{m}$ and also observed increased surface roughness with increasing the shot diameter. Reduced surface roughness was observed for the shot of $850 \mu \mathrm{m}$ in diameter. Nevertheless, one must approach these results with caution because for the shot with the diameter ranging $125-250 \mu \mathrm{m}$, a longer peening time and a higher penning pressure were used. Surface roughness also depends on the shot material. The use of ceramic beads and CrNi steel shot having $600 \mu \mathrm{m}$ in diameter produced a smoother surface for the shot with a higher specific weight [23].

SEM examination results (Fig. 5a) of surface morphology of the as-printed specimens reveal the presence of surface features that are typical of additive manufactured parts, such as unmelted metal powder grains and weld pool collapse along the laser melted track. Under external load, they can be the location of microcrack initiation on the surface, consequently leading to reduced fatigue strength of a given detail. The formation of structural discontinuities due to weld pool collapse results from a too deep penetration of the laser beam into the substrate or the previously sintered layer, which was also highlighted in studies [25-27]. The as-fabricated (Ref.) specimen has minimal density and sufficient quality for further shot peening processing. On the other hand, Uğur Solakoğlu et al. [28] confirmed that in the case of DMLS of nickel-based superalloy feedstock, specimen surface quality can be improved by increasing laser power while at the same time reducing scanning speed and layer thickness. However, the commercial 17-4PH steel-powder provided by EOS GmbH should be deposited according to the manufacturer's requirements. Consequently, the parameters applied in this study were fixed and made compliant with the manufacturer's recommendations; finally, they agreed with the 17-4PH powder deposition procedures described in other studies, e.g. by Murr et al. [29] (laser power $200 \mathrm{~W}$, scan speed $1000 \mathrm{~mm} / \mathrm{s}$ and laser spot size $0.1 \mathrm{~mm}$ ) and Cheruvathur et al. [30] (laser power $195 \mathrm{~W}$, scan speed $1000 \mathrm{~mm} / \mathrm{s}$ and laser spot size $0.1 \mathrm{~mm}$ ).
Shot peening causes plastic deformation on the surface, with visible impact cavities in the form of craters or spherical ball imprints, as it can be observed for steel shot in Fig. $5 \mathrm{~b}$ and c. In addition to that, on the surface modified with nutshell granules (Fig. 5d and e) one can observe the presence of laser beam melted tracks, which is a characteristic surface texture created by laser sintering. When the peening process is conducted using nutshell granules, the application of a higher peening pressure appears to be too invasive and results in the formation of large irregular cavities on the surface. On the other hand, when the shot peening using nutshell granules is performed with a pressure of $0.3 \mathrm{MPa}$, this may help cleanse the surface off the unmelted metal powder grains or sticking particles after laser sintering. For the case of small-size shots below $50 \mu \mathrm{m}$, one can observe the pressing of whole shot particles into the specimen surface, like it was observed for ceramic beads in Fig. 5f, $g$ and $h$.

Figure 6 shows the phase composition changes, and Table 5 compares the grain sizes of additive manufactured $17-4 \mathrm{PH}$ specimens, both in as-fabricated state and after shot peening with different pressures and blasting media. The X-ray diffraction (XRD) results demonstrate that the microstructure of the as-fabricated $17-4 \mathrm{PH}$ specimen consists of martensite $(\alpha)$ and retained austenite $(\gamma)$ (Fig. 6), which may have both detrimental and beneficial effects on the mechanical and corrosion properties of this grade of stainless steel. This observation agrees with the results of a study by Cheruvathur et al. [30], who obtained a similar microstructure for additive manufactured 17-4PH steel. Fortunately, the selected shot peening parameters make it possible to modify both the phase composition and the grain size of additive manufactured specimens. With an exception of nutshell granules, ceramic beads and steel shot significantly affect phase development—namely, they reduce the austenite content by inducing martensitic transformation (Fig. 6). A comparison of phase results obtained for the Ref. specimen and modified specimens C3, C6, C3 and $\mathrm{C} 6$ confirms the predominance of a tough martensitic structure. The specimen blasted with nutshell granules at $0.6 \mathrm{MPa}$ (N6) exhibits a small decrease in the $\gamma$ phase, while negligible phase changes can be identified for the specimen peened at $0.3 \mathrm{MPa}(\mathrm{N} 3)$ compared to the unpenned structure of 17-4PH steel. On the other hand, the phase analysis results (see Table 5) indicate a slight grain refinement for the two nutshell-peened specimens. An analysis of these results makes it clear that the utilisation of ceramic beads and steel shot definitely leads to refined grain size, with the highest grain-refinement obtained for specimen C6 (its average crystallite size is $14.6 \mathrm{~nm}$; Table 5, when compared to the Ref. specimen microstructure consisting of $22.0 \mathrm{~nm}$ grains. According to the Hall-Petch theory, grain refinement should lead to increased strength of polycrystalline materials [31]; 
Fig. 5 Surface morphology of test specimens: a Ref.-asfabricated specimen, and shootpeened surfaces: b S3, c S6, d N3, e N6, f C3, g C6, h C6enlarged area of (g), SEM

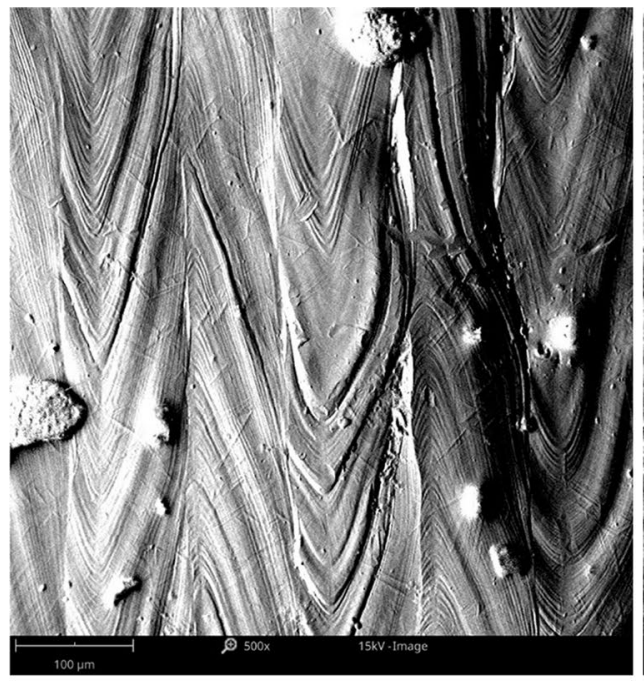

(a)

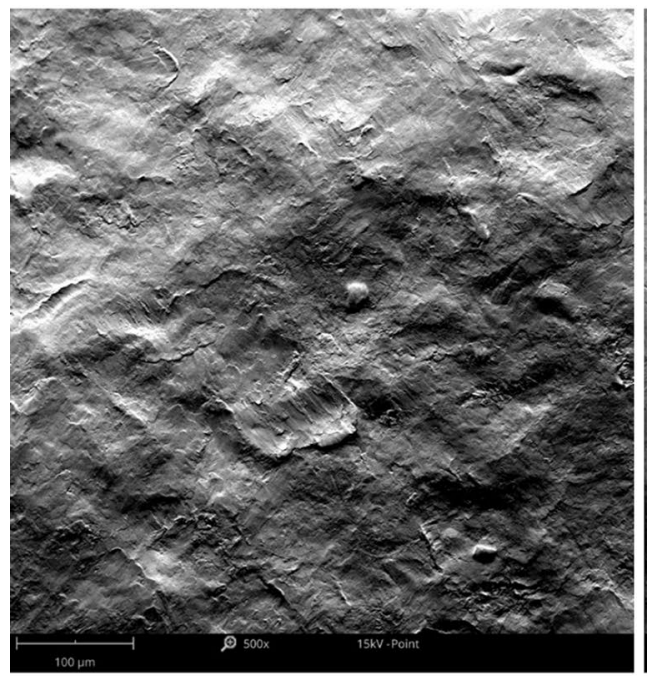

(c)

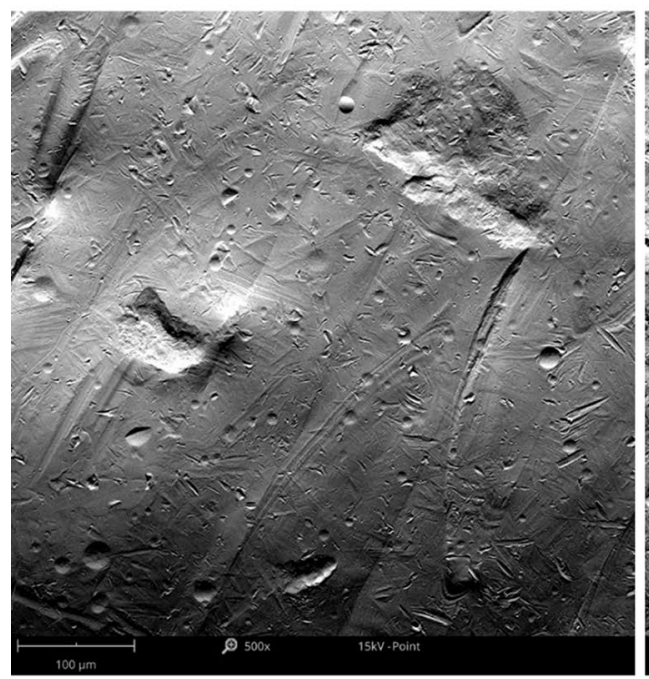

(e)

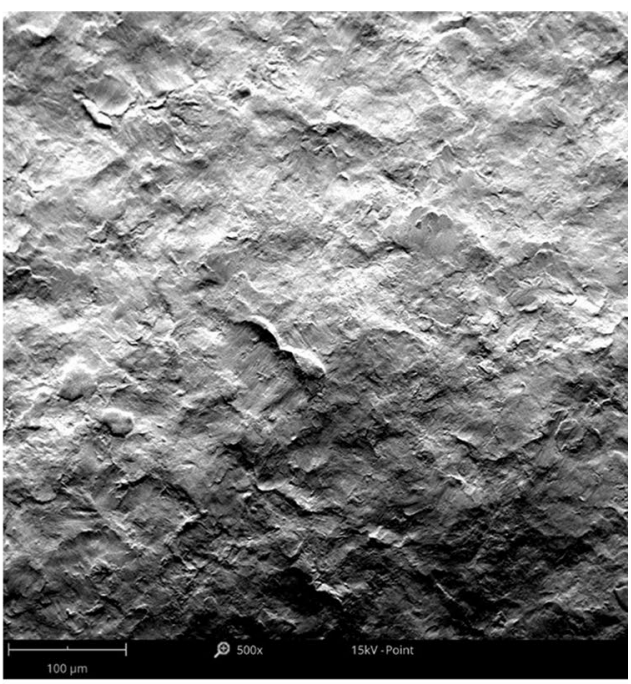

(b)

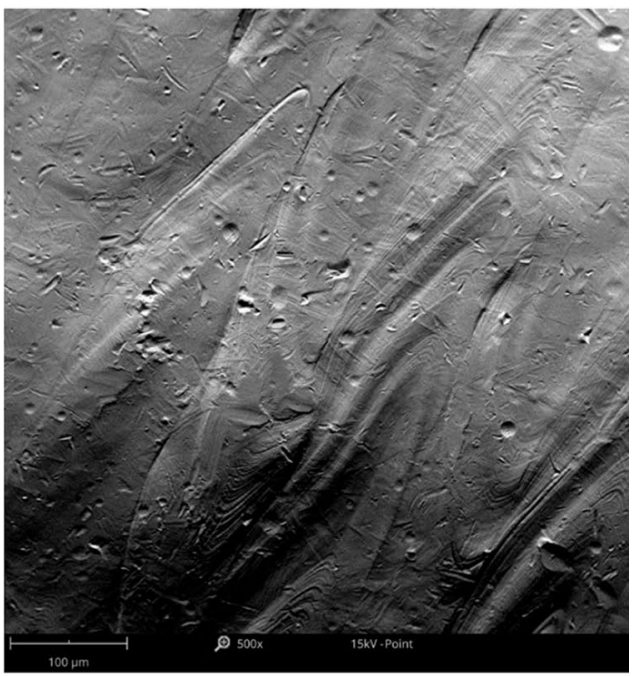

(d)

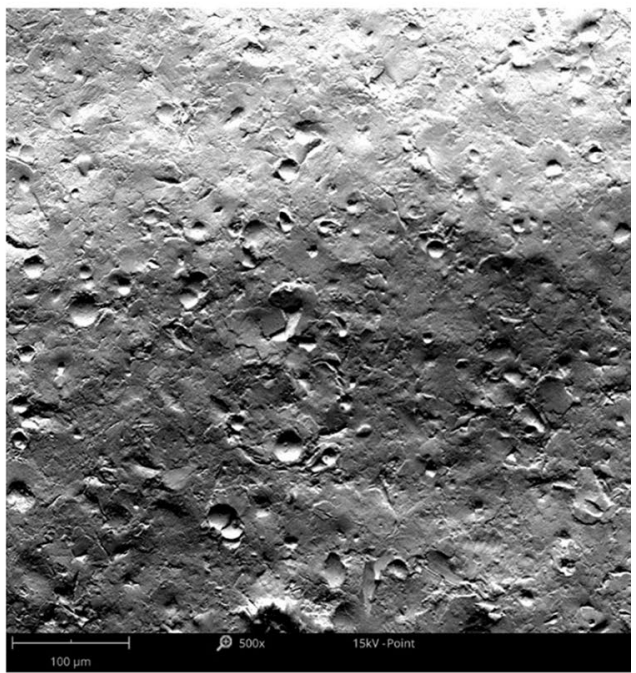

(f) 
Fig. 5 (continued)

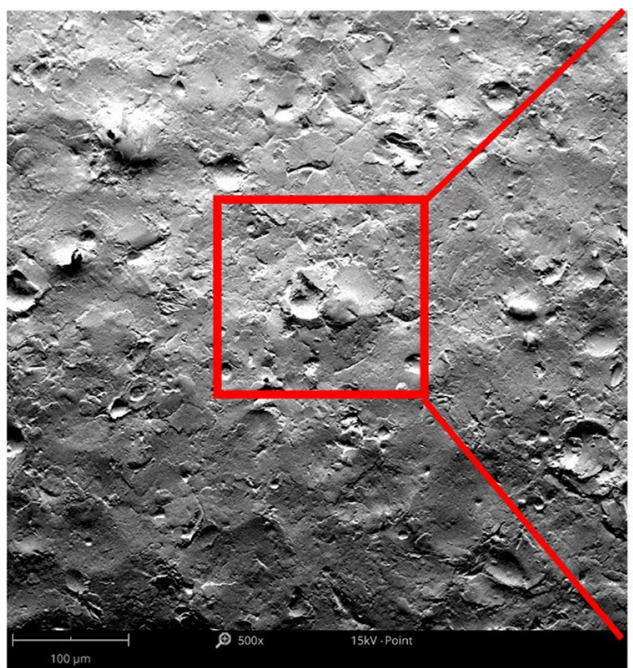

(g)

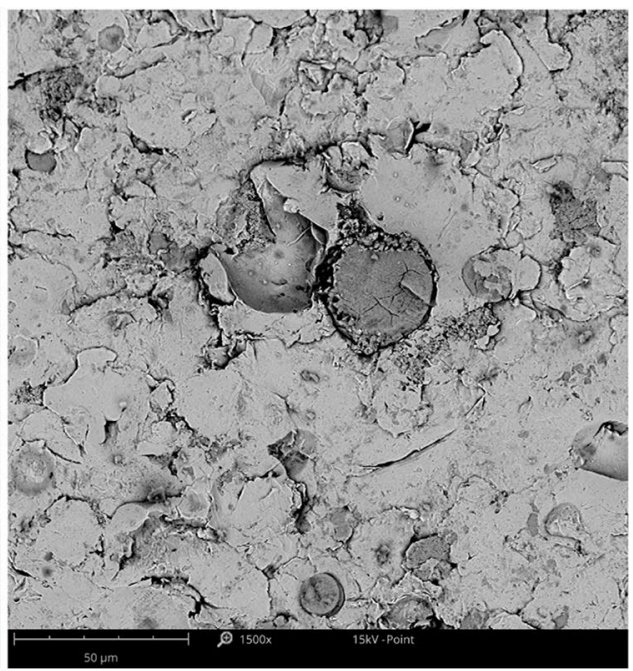

(h) hence, it should have a positive effect on hardness and wear resistance of peened surfaces, which is discussed in further sections.

\subsection{Microhardness measurements}

Microhardness results (Fig. 7) show that the mean hardness of all shot-peened surfaces has increased when compared to the reference DMLS samples. The mean hardness of the unmodified samples fabricated by DMLS is $247 \mathrm{HV} \pm 9 \mathrm{HV}$, which agrees with the value declared by the manufacturer EOS GmbH, i.e. $230 \pm 20 \mathrm{HV}$. Compared to the reference samples, the smallest increase in hardness is observed for the surfaces modified with nutshell granules. The hardness of the surfaces peened with this medium has only increased by approx. $\sim 27 \%$. The highest surface hardening is obtained for the surfaces peened with ceramic beads, where the hardness increased by approx. 119\% (mean $542 \mathrm{HV}$ for the peening pressure $0.6 \mathrm{MPa}$ ). The surfaces peened with steel shot show similar hardness values - their hardness increased by approx. $\sim 116 \%$ compared to the reference surface, i.e. mean $247 \mathrm{HV}$. However, it should be remembered that for the case of the surfaces modified by ceramic beads, the shot size was from two to three-times smaller. The observed surface hardness increase can be explained by the fact that the shotpeened specimens show surface nanocrystallization, which leads to material hardening [14, 32]. According to the results of XRD phase analysis given in Fig. 6 and Table 5, plastic deformation causes grain size refinement and increased density of dislocation on the surface [31], while the remnants of hard shot or-for the case of smaller diameters-of even entire shot particles are pressed (stuck) into the material (see Fig. 5), which, additionally, causes a significant local increase in microhardness.
A model of changes occurring on the surface of material was proposed by Kameyama and Komotori [14]. The surface of a workpiece is changed in such a way that shot particles blasting the material can break the continuity of the surface material and thus cause it to spall, while at the same time the shot particles break off and remain on the surface. With every successive blast, the shot particles remaining on the surface are "pressed" into the material structure more deeply, which leads to local hardening and creation of a lamellar structure that is characteristic of this type of surface treatment.

\subsection{Wear and surface morphology after the ball-on-disc test}

Obtained coefficients of friction (COF) are given in Table 6, while the changes in COF with sliding distance are shown graphically in Fig. 8. The tribological results demonstrate that the lowest (and very similar) values of COF are observed for the Ref. sample. This probably results from the fact that there is unmelted metal powder on the top surface (Fig. 5a), which — in combination with relatively low surface roughness (Table 4) -facilitates sliding action. Nevertheless, the changes in the COF of the tested surfaces are within a range of $0.625 \div 0.687$; considering the standard deviation, it can be claimed that these differences are statistically insignificant. It can be observed that peening pressure has practically no significant impact on COF when the same peening medium is used (compare S3 and S6, as well as C3 and C6). Here, significant differences can only be observed between N3 and N6, see Fig. 8. This behaviour can be explained by high invasiveness of the treatment under pressure. As it was mentioned previously, the use of high pressure in combination with sharp-edged nutshell shot leads to the formation of 

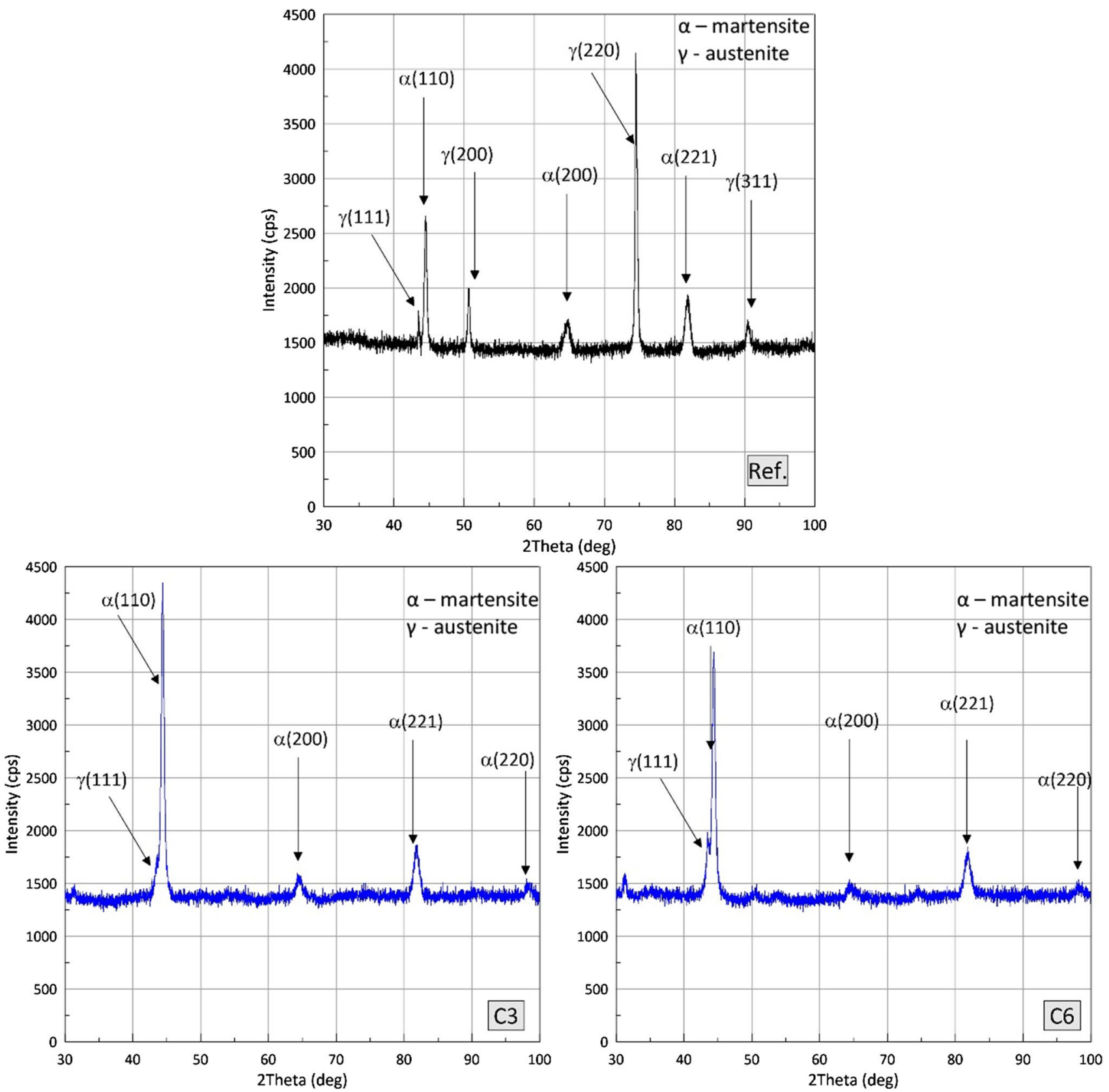

Fig. 6 Phase compositions of as-fabricated and shot-peened additive manufactured 17-4PH, XRD

large irregular cavities in the material (see Fig. 5e), which results in a higher COF of specimen N6. In addition to that, given the comparable surface hardening of the surfaces peened with steel shot and ceramic beads, one can observe a relatively higher $\mathrm{COF}$ for specimens $\mathrm{C} 3$ and $\mathrm{C} 6$. The surfaces modified by ceramic beads show the presence of remnants of the hard ceramic shot that generates higher COF, as confirmed by the SEM results of surface morphology in Fig. $5 \mathrm{~g}$ and $\mathrm{h}$.

An analysis of the COF vs. sliding distance plots (Fig. 8) demonstrates that all surfaces show maximal values at an early stage of the test. After a distance of $80 \mathrm{~m}$, the COF decreases and becomes stabilized. This behaviour of the tested surfaces is strongly associated with surface morphology and the degree of peened surface hardening. Having covered the distance of $80 \mathrm{~m}$, the WC ball is outside the modified zone of the material, and thus a slight increase in COF can be observed.

Figure 9 shows the wear factor $(K)$ of the shot-peened surfaces. It can be observed that the wear resistance of all modified surfaces increases with increasing peening pressure. The highest wear resistance under technically dry 

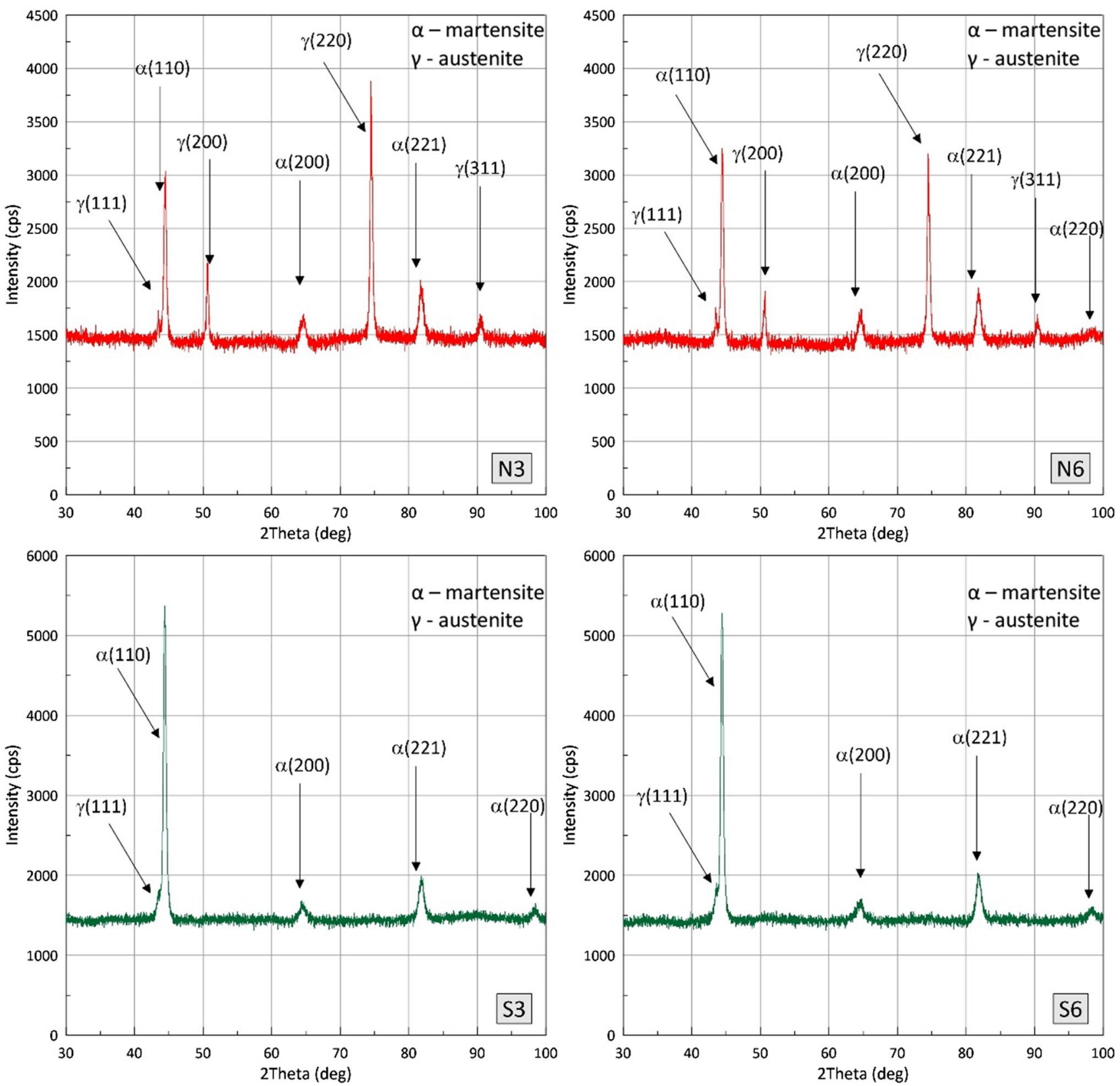

Fig. 6 (continued)

friction conditions was achieved for the surfaces peened with ceramic beads. Considering the minimum and maximum wear rates and standard deviation, the results are comparable for all surfaces modified with the use of the near-spherical shot. The highest resistance to sliding wear was achieved by $\mathrm{C} 6$; compared to the reference surface, this specimen surface has a nearly $35.6 \%$ lower wear factor. The highest $\mathrm{K}$ values were obtained for specimens N3 and N6, see Fig. 9. Generally, wear is strongly connected with surface hardness [33]. Hence, high surface hardness usually implies lower wear factor K. The results of this study confirm that the application of ceramic beads leads to the formation of martensitic structure and microstructure refinement (see XRD results in Fig. 6 and Table 5), which results in increased hardness of the metallic surface (Fig. 7) and, finally, decreased wear factor (see Fig. 9). These results agree with the findings reported by Gürgen [34], who associated refinement and hardness increase with reduced wear rate. In another study [35], these authors have shown that higher material hardness acts beneficially against abrasive wear by withstanding the ploughing effect in the sliding zone. 
Table 5 Results of crystallite size of the unpeened and shot-peened 17-4PH steel specimens presented in Fig. 6, XRD

\begin{tabular}{llll}
\hline Specimen & Position, [ ${ }^{\circ}$ 2Th.] & $\begin{array}{l}\text { Crystallite } \\
\text { size, nm }\end{array}$ & $\begin{array}{l}\text { Identified } \\
\text { phase struc- } \\
\text { ture }\end{array}$ \\
\hline Ref. & $44.486(4)$ & 22.0 & $\alpha(110)$ \\
S3 & $44.370(2)$ & 18.5 & $\alpha(110)$ \\
S6 & $44.378(2)$ & 18.5 & $\alpha(110)$ \\
N3 & $44.430(3)$ & 20.4 & $\alpha(110)$ \\
N6 & $44.412(2)$ & 20.9 & $\alpha(110)$ \\
C3 & $44.363(2)$ & 15.8 & $\alpha(110)$ \\
C6 & $44.357(3)$ & 14.9 & $\alpha(110)$ \\
\hline
\end{tabular}

The surfaces peened with sharp-edged nutshell granules do not exhibit considerably increased hardness, despite the highest increase in their roughness parameter $R_{\mathrm{a}}$. Their wear is rather a result of higher roughness peak shear. According to Al-Mangour and Yang [36], the lower wear of shotpeened 17-4PH steel specimens results from elevated grainrefinement effect and severe plastic deformation, which agrees with the results of this study. Similar observations were made by Wang et al. [37], who investigated the wear resistance of low carbon steel after shot peening. Their study confirmed that increased hardness results from fine-grain surface and decreased ball penetration depth, which-in turn-leads to reduced ploughing and micro-cutting.

Wear mechanisms were examined by scanning electron microscopy (SEM), and a comparison of worn surfaces is given in Fig. 10. An analysis of the data in this figure reveals two dominant wear mechanisms for all tested surfaces: adhesive smearing and low-cycle fatigue. The adhesive wear mechanism is manifested by smearing of the grooved material along the ball direction, while low-cycle fatigue is caused by repeated upsetting (by the ball) of the same volume of the material. This behaviour was confirmed for both as-fabricated (Fig. 10a, b) and shot-peened 17-4PH steel surfaces (Fig. 10c-h). Adhesive wear can be observed for all tested surfaces and is manifested in smearing, which results in the transfer of the worn material through the wear trace. In addition to that, due to material fatigue, microcrack propagation perpendicular to the ball direction can be observed along the wear track, see Fig. 10c. The propagating and growing cracks cause the spallation of worn material, as shown in Fig. 10c-g). The ceramic shot-peened surfaces show the presence of the shot, as confirmed by energy-dispersive X-ray (EDS) analysis (Fig. 10h). Hard remnants of

Table 6 Comparison of the coefficients of friction $(\mathrm{COFs})$ determined for the tested surfaces

\begin{tabular}{lll}
\hline Specimen & COF \\
\cline { 2 - 3 } & Mean & $\begin{array}{l}\text { Standard } \\
\text { deviation }\end{array}$ \\
\hline S3 & 0.640 & 0.058 \\
S6 & 0.646 & 0.045 \\
N3 & 0.631 & 0.105 \\
N6 & 0.662 & 0.076 \\
C3 & 0.687 & 0.045 \\
C6 & 0.685 & 0.044 \\
Ref. & 0.625 & 0.024 \\
\hline
\end{tabular}

Fig. 7 Surface hardness of unpeened (Ref.) and shotpeened specimens of $17-4 \mathrm{PH}$ stainless steel

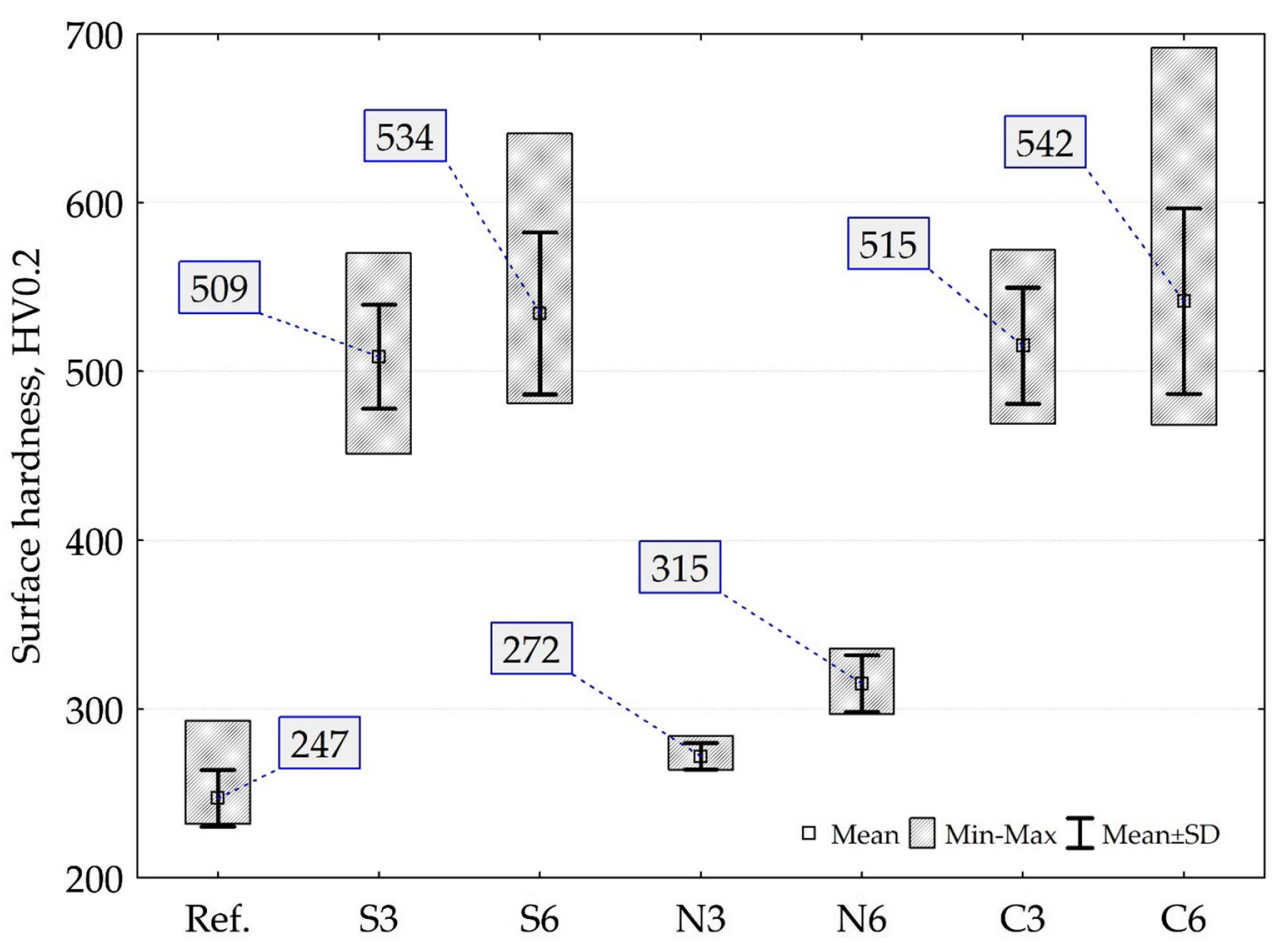


Fig. 8 Curves illustrating the relationship between coefficient of friction and sliding distance for surfaces modified by different shot types
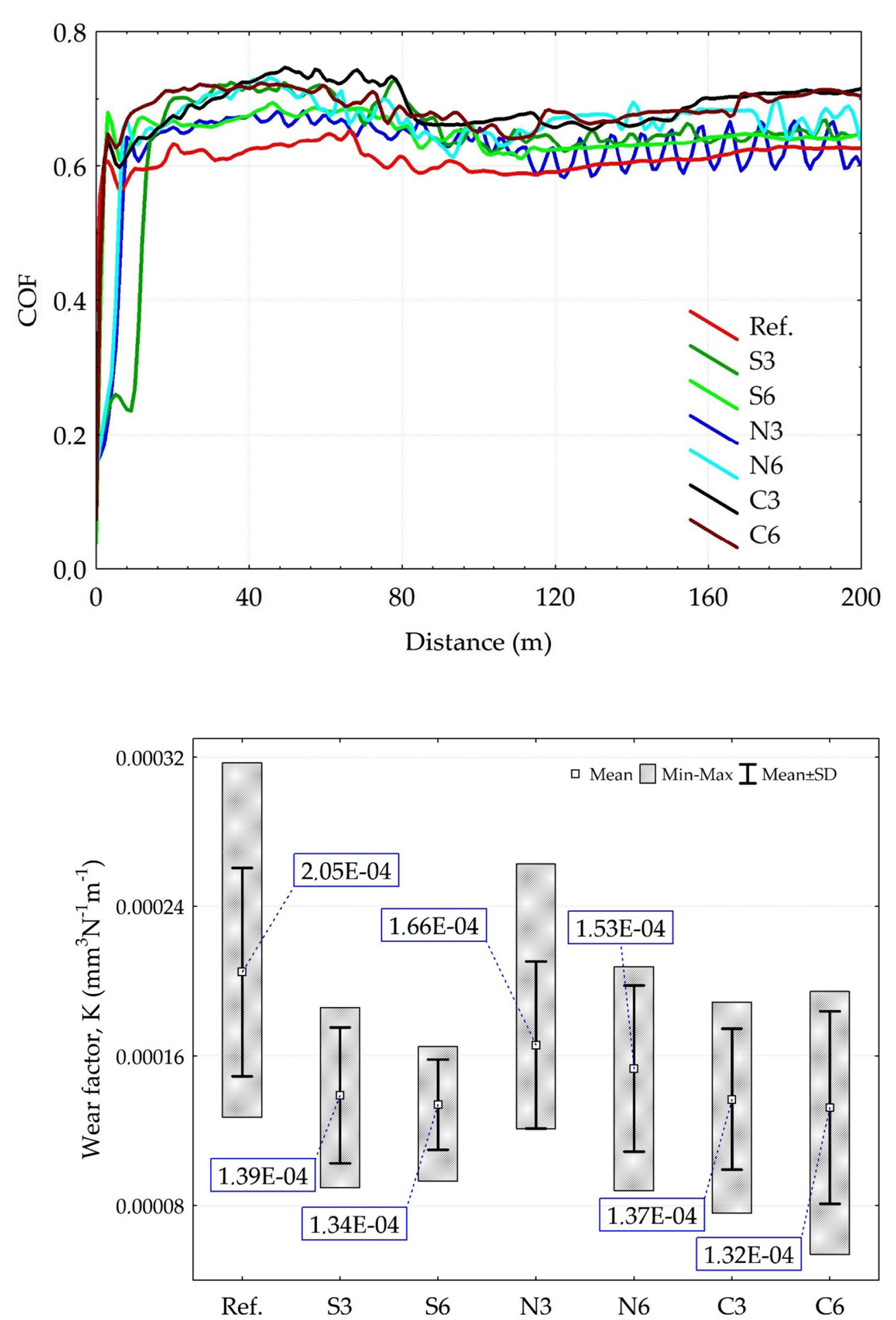

Fig. 9 Wear factor $K$ of unmodified (Ref.) and shot-peened surfaces the ceramic shot are an obstacle to the ball material and thus act as a third-body, which leads to abrasive grooving and more intense surface deterioration of the AM 17-4PH specimens.

According to the fundamental literature of the subject [33], wear mechanisms rely on many factors, including the applied load, countersample type, test environment, and sliding distance. Changes in sliding conditions can result in a modified wear behaviour. Wang et al. [37] conducted tribological testing of low carbon steel with loads below $4 \mathrm{~N}$, finding the sliding wear mechanism to be dominant and have the form of micro-cutting and parallel grooving. The adhesive smearing wear behaviour was also confirmed by the results of a study [38] which investigated materials 

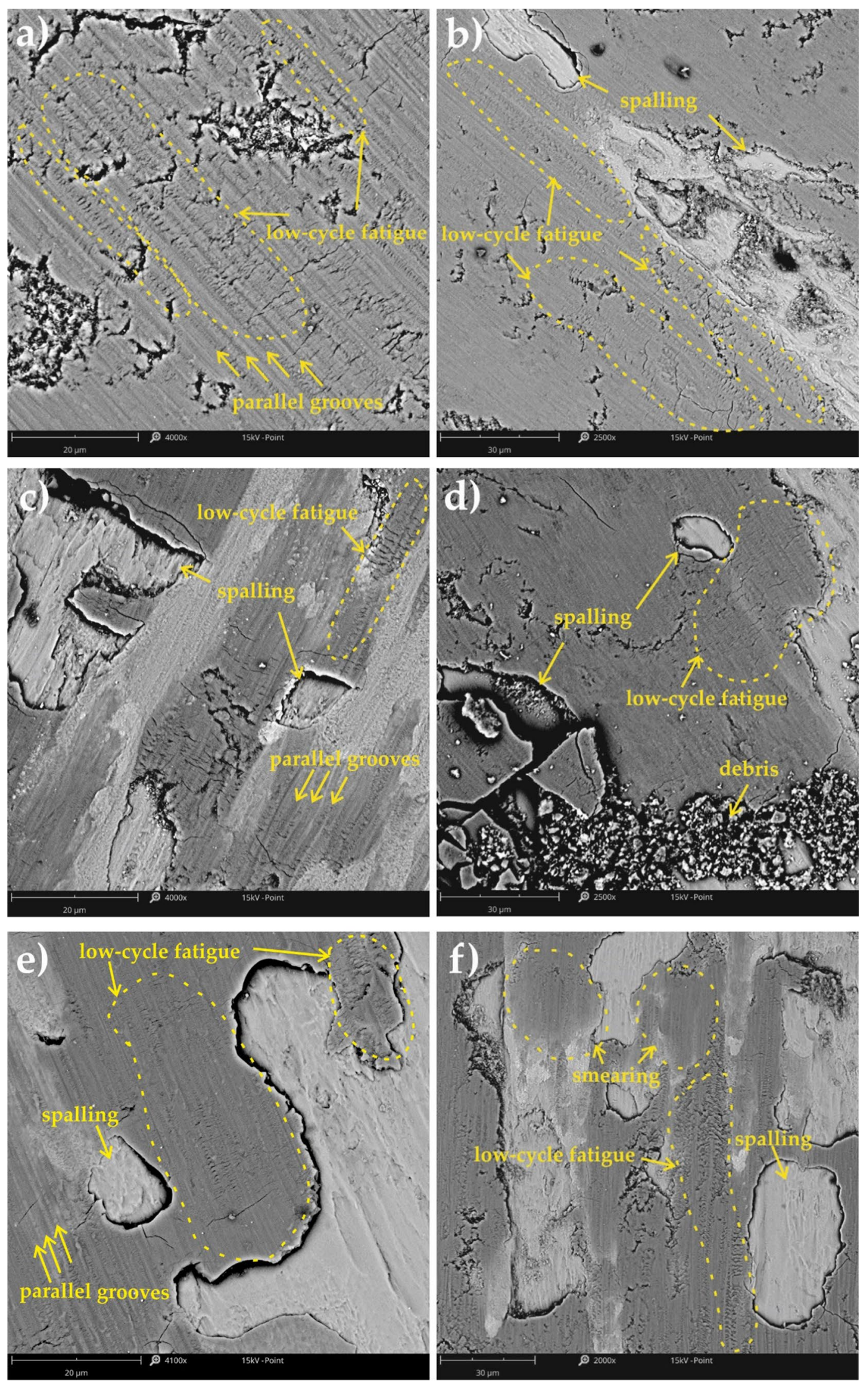

Fig. 10 Worn surfaces of a and b Ref. sample, c S3, d S6, e N3, f N6, g C3, and h C6, SEM-EDS 

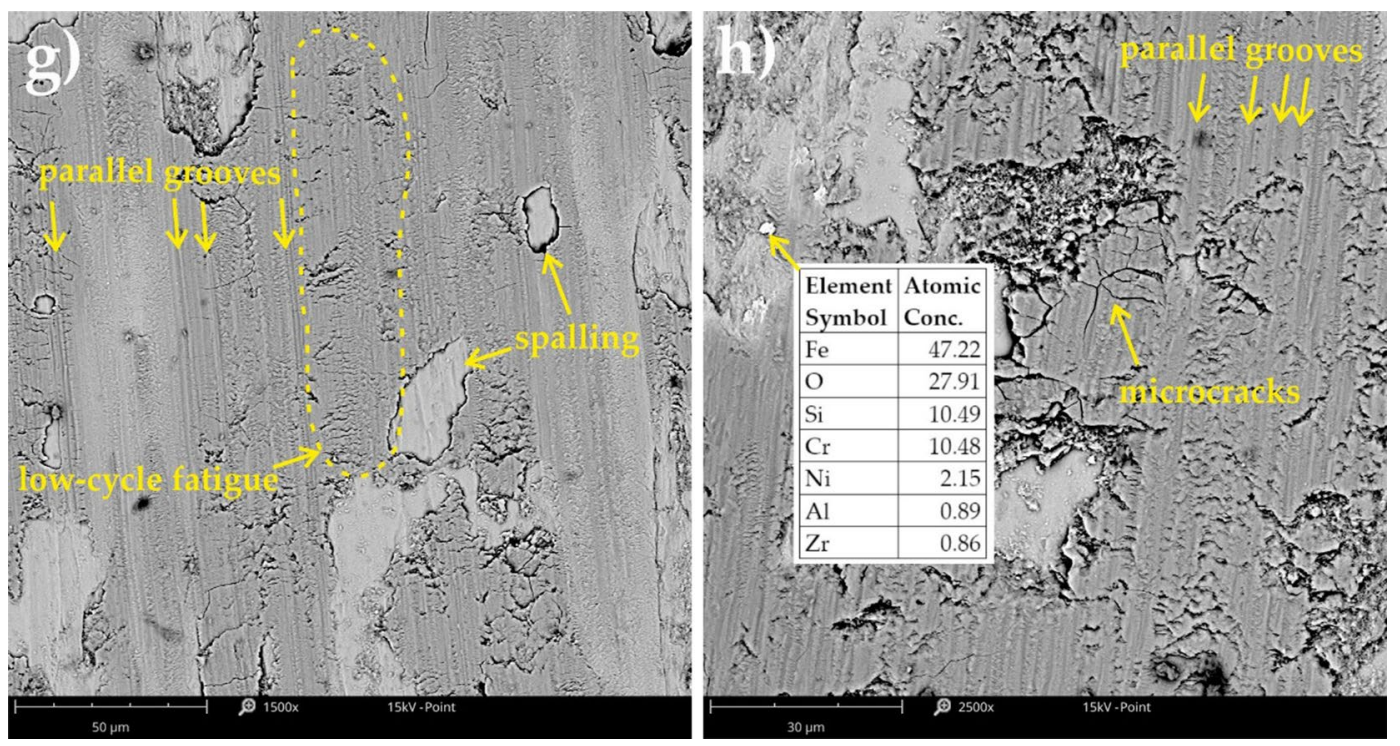

Fig. 10 (continued)

such as stainless steel, brass, pure copper and aluminium alloy subjected to load of $10 \mathrm{~N}$ and a sliding distance of $200 \mathrm{~m}$. The study showed that with increasing the load (6 and $8 \mathrm{~N}$ ), the dominant sliding wear changes into fatigue cracking, which leads to spalling of the worn surface. A study [39] on rotary friction welding of 17-4PH steel confirmed that increasing the applied load from 5 to $10 \mathrm{~N}$ leads to fatigue wear. The study reports the presence of a crack running along the sliding direction, which was formed due to repetitive heat and stress cycles resembling fatigue cracking. Yang et al. [40] investigated the wear anisotropy of $316 \mathrm{~L}$ stainless steel specimens fabricated by selective laser melting, finding that under a load of $1 \mathrm{~N}$ shear bonds could be identified, which indicates that the main failure mechanism is slipping. With a normal load increase to $5 \mathrm{~N}$, the cracking mechanism becomes dominant, which results in the formation of severely worn grooves and many parallel cracks. In turn, Sanjeev et al. [41] showed for additive manufactured $17-4 \mathrm{PH}$ steel tested under dry sliding wear conditions, adhesive smearing is the dominant wear mechanism. The review of the above-mentioned studies indicates that fatigue cracking initiates at a load of $10 \mathrm{~N}$, which is the load value applied in this study.

\subsection{Corrosion resistance: potentiodynamic tests}

Potentiodynamic test results obtained for the surfaces modified by different shot types are given in Fig. 11. An analysis of the Tafel polarisation curves demonstrates that reduced corrosion resistance is primarily connected with the surface development (roughness profile) induced by shot peening. The highest corrosion resistance (high potential and low current density) is obtained for the ceramic shot-peened surfaces. Apart from the nature of surface finish provided by this treatment, the corrosion performance of these specimens may also result from the fact that the ceramic beads penetrating the surface act as a non-corrosive insulation material. Another group of surfaces with the desired properties are those modified by the $\mathrm{CrNi}$ steel shot. The optimum properties are obtained for a lower roughness surface peened with a pressure of $0.3 \mathrm{MPa}$, i.e. specimen S3. According to the data in Fig. 11, the lowest corrosion resistance is obtained for the surfaces peened with sharp-edged nutshell granules. In this respect, the surface of specimen N6 exhibits much worse properties than the reference surface. This can be attributed to the already-mentioned fact (see Fig. 5) that for the surfaces peened with nutshell granules the $0.6 \mathrm{MPa}$ penning pressure is too invasive and may lead to the formation of large irregular cavities in the material, thus extending the corrosion active area. It is worth noting that for almost all tested surfaces (except N6), the potential $E_{\text {corr }}$ ranges $-300 \div 300 \mathrm{mV}$, which - as far as body fluid testing is concerned-is considered safe in terms of biocompatibility of medical devices [42, 43]. Żebrowski et al. [18] showed that ceramic shot-peened materials exhibit increased corrosion resistance when compared to those treated with steel shot and nutshell granules, and that this phenomenon is associated with surface roughness profile. Jelliti et al. [32] demonstrated that apart from surface roughness, grain size induced by shot peening is another key factor affecting corrosion performance of materials. According to these authors, increased corrosion resistance of shot-peened samples results from grain refinement due to nanocrystalline structure formation. The literature review shows that the relationship between 
Fig. 11 Potentiodynamic polarization curves in $0.9 \% \mathrm{NaCl}$ solution

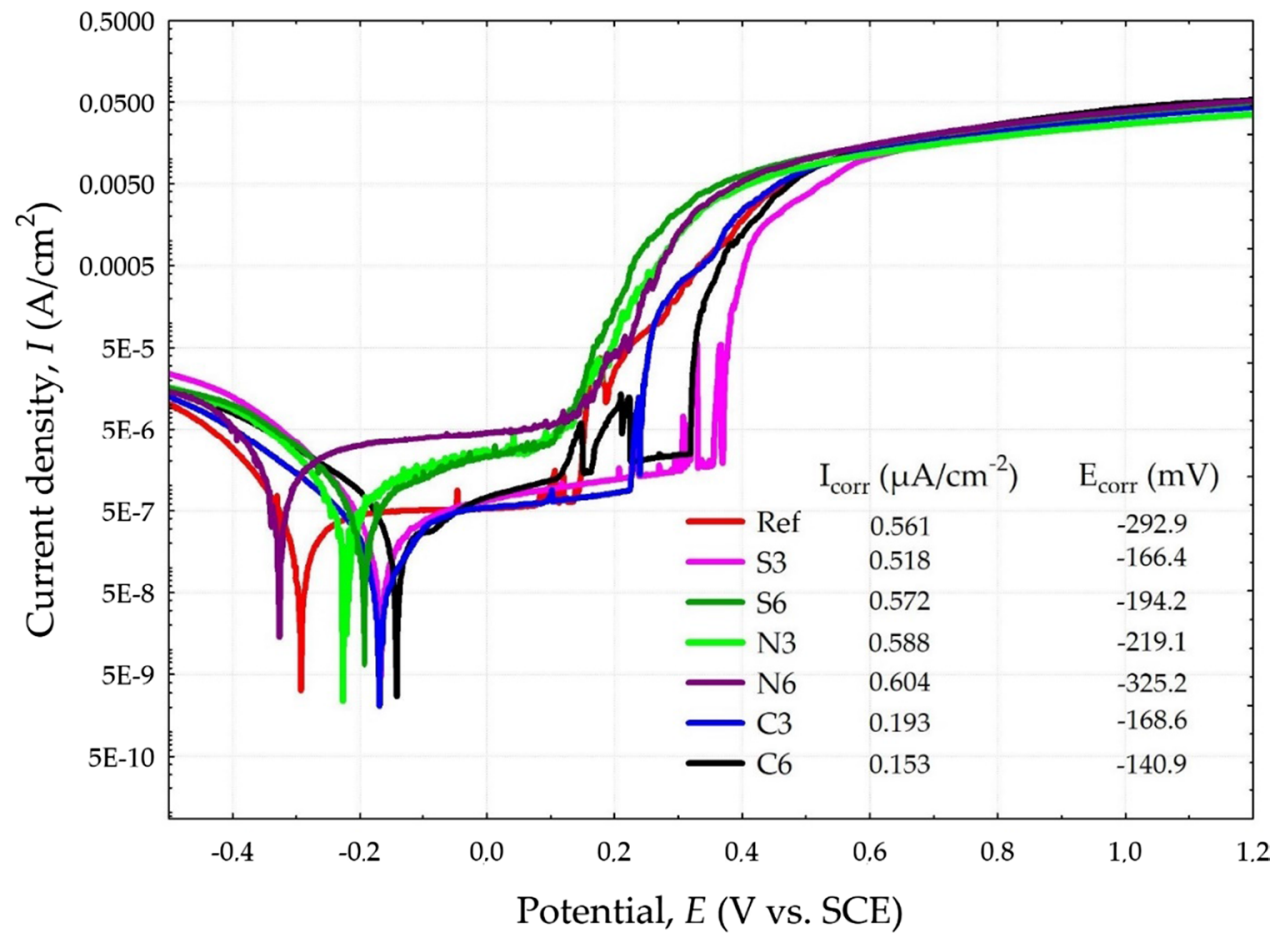

grain size and corrosion resistance of materials is debatable. On the one hand, there exist studies claiming that reduced grain size may lead to increased corrosion rate [44, 45]; on the other, there are studies demonstrating that corrosion resistance increases with decreasing grain size [46, 47]. Qiao et al. [48] proposed a nucleation and growth model of surface passivation film of low alloy steel for peened surfaces. They claimed that the microstructure of the unpeened specimen was an equiaxed ferrite structure having a low grain boundary density and that the passivation film was mainly nucleated at these interfaces. The surface layer of the specimen formed nano-layered grains under shot peening conditions, and the grain boundary density increased sharply. The passive film nucleates instantaneously at these interfaces and grow uniformly in all directions along the surface plane [48], as a result successfully increasing the corrosion resistance of the shot-peened structure. Summing up, the literature review confirms the XRD results discussed in Sect. 3.1 and thus proves that shot peening induces grain-refinement (see Table 5), which facilitates the corrosion resistance of the modified surface layer (Fig. 11).

A detailed microscopic and profilometric analysis of the specimen surface after corrosion testing (Figs. 12 and 13) reveals the presence of numerous corrosion pits (black regions in Fig. 12) that are characterized by a semi-round shape, as shown in Fig. 13. The growth of corrosion pits is induced by the occurrence of a breakthrough potential (Fig. 11). Consequently, the anodic curves for all specimens are characterized by a wide passivation plateau. In the $\mathrm{V}$ vs. SCE range of $0.1 \div 0.4$ the current density suddenly increases, which indicates the formation of corrosion pits, as shown in Figs. 12 and 13. Nevertheless, the pitted surface morphology (Fig. 12) should be analysed in relation to quantitative results. Thus, computer image analysis of the corroded areas demonstrate that the most extensive pits are characterised by higher maximum ferret diameters ranging $0.70 \pm 0.18 \mathrm{~mm}$ and $0.84 \pm 0.26 \mathrm{~mm}$ for specimens $\mathrm{S} 6$ and N6, respectively; the maximum ferret diameter ranging $0.51 \pm 0.15 \mathrm{~mm}$ can be observed for specimen C6. In turn, the Ref. specimen has the maximum ferret diameter of $0.71 \pm 0.18 \mathrm{~mm}$. The lowest percentage rate of pitted area amounting to $5.7 \%$ can be observed for the smoothest surface of specimen C6; specimen S3 exhibits $9.1 \%$ of surface pitting, while specimen N9 shows the highest value of surface pitting amounting to $14.2 \%$. Other specimens, Ref. included, exhibit an approx. $10 \%$ of surface pitting. In addition, the profilometry results given in Fig. 13 reveal that the highest increase in the roughness parameter $S_{\mathrm{a}}$ occurred for the most corroded surfaces. These findings agree well with the initial roughness results of the shot-peened surfaces, see Table 3. It should be emphasized that the lowest roughness was obtained for specimen C6 which also exhibits higher grain refinement (as confirmed by XRD results, see Table 5). These findings support the claim that the surfaces with the lowest crystallite size and the smoothest surface roughness are characterised by the superior corrosion behaviour.

Summing up, the experimental results demonstrate that the additive manufactured $17-4 \mathrm{PH}$ specimens modified by shot peening using ceramic beads and a pressure of 0.6 MPa exhibit the optimum surface morphology, hardness 

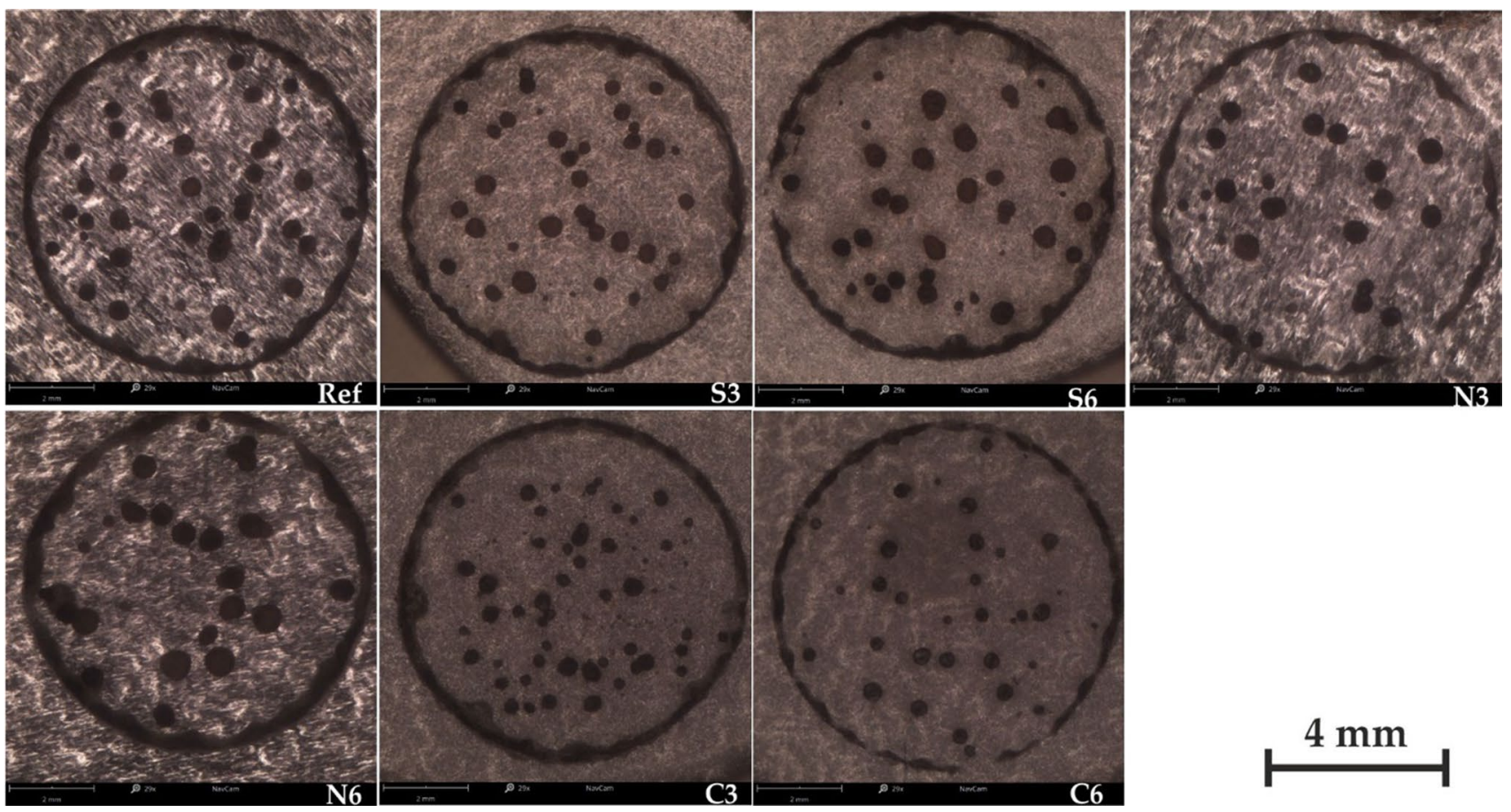

Fig. 12 Surface morphology after corrosion testing, corroded area $0.5 \mathrm{~cm}^{2}$

and microstructure, and thus improved wear and corrosion performance.

\section{Conclusions}

The experimental results of this study lead to the following conclusions:

- An analysis of the surface morphology of the as-fabricated specimens reveals the presence of typical DMLS surface features such as unmelted metal powder grains and weld pool collapse along the laser melted track. The shot-peened surfaces contain the fragments of shot.

- Compared to the reference specimen surface, the surface roughness of the specimens peened with nutshell granules and steel shot increases with increasing peening pressure; the opposite trend can be observed for the surfaces modified with the use of ceramic beads.

- The application of shot peening refines specimen microstructure and-with the exception of specimens peened using the nutshell shot-induces the formation of martensite $(\alpha)$ and the reduction of retained austenite $(\gamma)$. For the specimens that were shot peened using ceramic beads, the crystallite size was refined up to $14.6 \mathrm{~nm}$, from the initial value of $22.0 \mathrm{~nm}$.

- The specimens peened with the CrNi steel shot, nutshell granules and ceramic beads show increased sur- face hardness. The highest increase in hardness was obtained for the surfaces modified by steel shot and ceramic beads using a peening pressure of $0.6 \mathrm{MPa}-\mathrm{it}$ increased by 116 and $119 \%$, respectively (mean: 534 $\mathrm{HV}$ and $542 \mathrm{HV}$ ), compared to the reference surface. This, in turn, led to improved wear resistance of the shot-peened additive manufactured 17-4PH steel.

- The tribological tests have shown that the shot-peened surfaces have a higher friction factor, while their wear factor is reduced. The friction factor increases with increasing peening pressure, while the wear factor decreases with increasing peening pressure. All examined surfaces show two dominant wear mechanisms, namely-adhesive and fatigue wear.

- The grain-refinement induced by shot peening led to improved corrosion resistance of the specimens. Among the surfaces tested in $0.9 \% \mathrm{NaCl}$ solution (for medical applications), the optimum properties are exhibited by the surfaces shot-peened with ceramic beads $>$ CrNi shot $>$ nutshell granules.

In light of the above results, it can be claimed that the optimum properties have been achieved for the additive manufactured 17-4PH steel specimens modified by shot peening using ceramic beads and a peening pressure of $0.6 \mathrm{MPa}$. 
Fig. 13 Morphology of the corroded surfaces of additive manufactured 17-4PH specimens after shot peening (scan area 25 $\mathrm{mm}^{2}$ ), optical profilometer
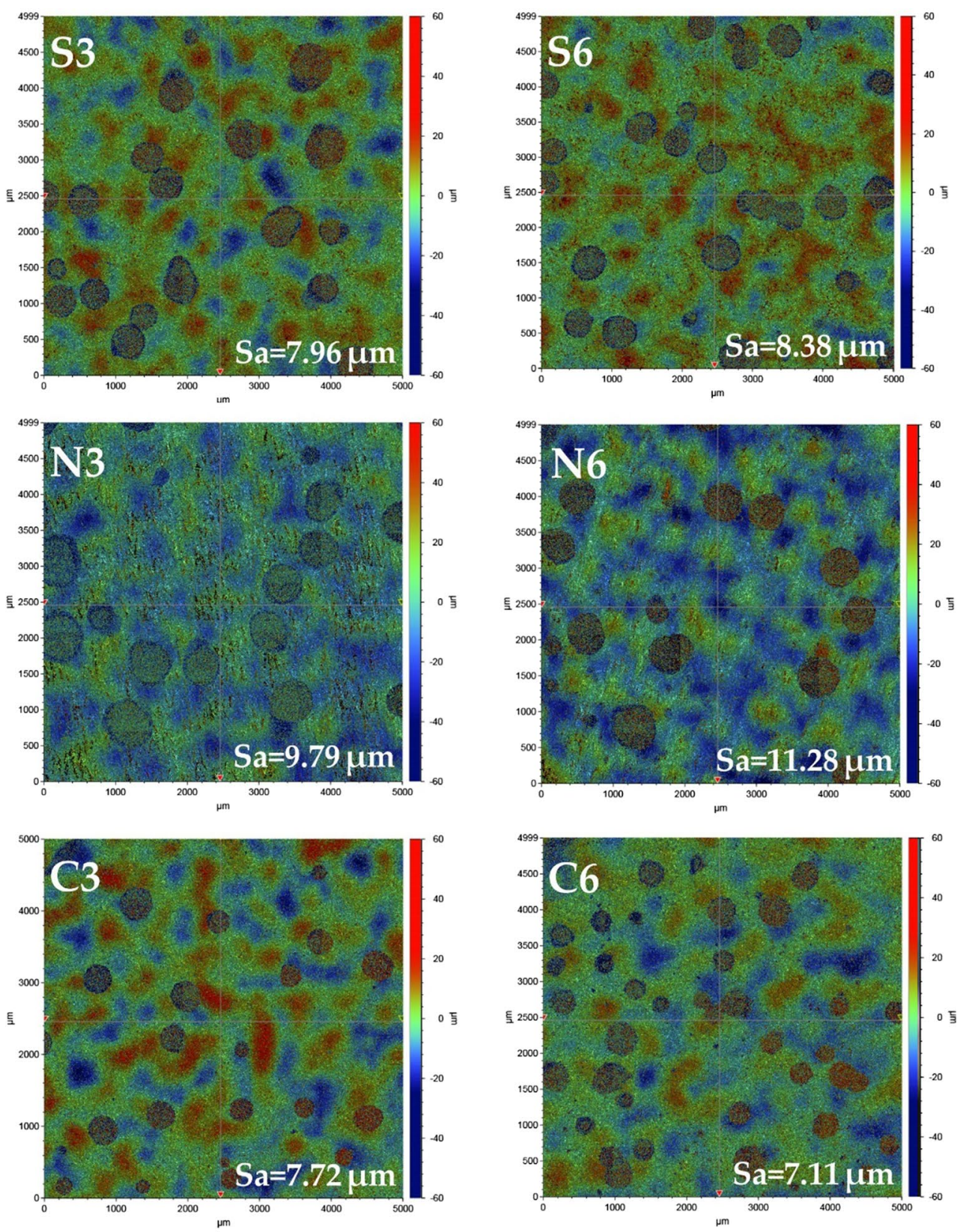

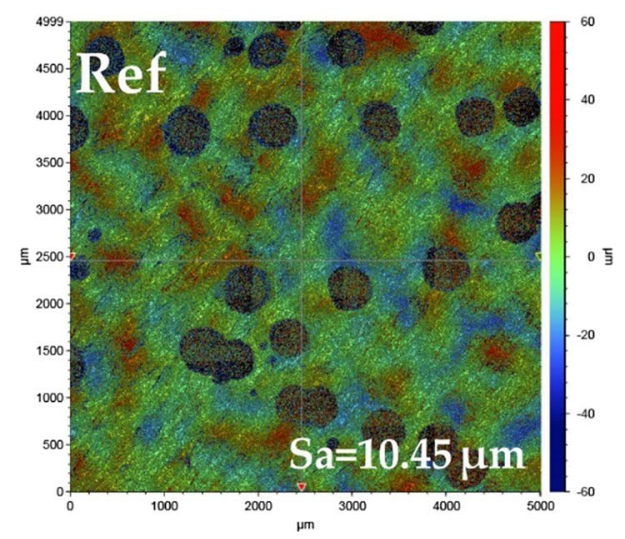


Acknowledgements The project/research was financed in the framework of the project Lublin University of Technology-Regional Excellence Initiative, funded by the Polish Ministry of Science and Higher Education (Contract No. 030/RID/2018/19).

Funding This study was funded by the Polish Ministry of Science and Higher Education (contract no. 030/RID/2018/19).

\section{Declarations}

Conflict of interest Authors declares no conflict of interest. Author B declares that he/she has no conflict of interest.

Ethical approval This article does not contain any studies with human participants or animals performed by any of the authors.

Open Access This article is licensed under a Creative Commons Attribution 4.0 International License, which permits use, sharing, adaptation, distribution and reproduction in any medium or format, as long as you give appropriate credit to the original author(s) and the source, provide a link to the Creative Commons licence, and indicate if changes were made. The images or other third party material in this article are included in the article's Creative Commons licence, unless indicated otherwise in a credit line to the material. If material is not included in the article's Creative Commons licence and your intended use is not permitted by statutory regulation or exceeds the permitted use, you will need to obtain permission directly from the copyright holder. To view a copy of this licence, visit http://creativecommons.org/licenses/by/4.0/.

\section{References}

1. Lashgari HR, Kong C, Adabifiroozjaei E, Li S. Microstructure, post thermal treatment response, and tribological properties of 3D printed 17-4 PH stainless steel. Wear. 2020;456-457: 203367. https://doi.org/10.1016/j.wear.2020.203367.

2. Palanisamy D, Senthil P, Senthilkumar V. The effect of aging on machinability of $15 \mathrm{Cr}-5 \mathrm{Ni}$ precipitation hardened stainless steel. Archiv Civ Mech Eng. 2016;16:53-63. https://doi.org/10.1016/j. acme.2015.09.004.

3. Zai L, Zhang C, Wang Y, Guo W, Wellmann D, Tong X, Tian Y. Laser powder bed fusion of precipitation-hardened martensitic stainless steels: a review. Metals. 2020;10:255. https://doi.org/10. 3390/met10020255.

4. Groarke R, Danilenkoff C, Karam S, McCarthy E, Michel B, Mussatto A, Sloane J, O’Neill A, Raghavendra R, Brabazon D. 316L stainless steel powders for additive manufacturing: relationships of powder rheology, size, size distribution to part properties. Materials. 2020;13:5537. https://doi.org/10.3390/ma13235537.

5. Macek W, Branco R, Trembacz J, Costa JD, Ferreira JAM, Capela C. Effect of multiaxial bending-torsion loading on fracture surface parameters in high-strength steels processed by conventional and additive manufacturing. Eng Fail Anal. 2020;118: 104784. https:// doi.org/10.1016/j.engfailanal.2020.104784.

6. Haghdadi N, Laleh M, Moyle M, Primig S. Additive manufacturing of steels: a review of achievements and challenges. J Mater Sci. 2021;56:64-107. https://doi.org/10.1007/s10853-020-05109-0.

7. Li C, Liu ZY, Fang XY, Guo YB. Residual stress in metal additive manufacturing. Procedia CIRP. 2018;71:348-53. https://doi.org/ 10.1016/j.procir.2018.05.039.

8. Kaszuba M, Widomski P, Białucki P, Lange A, Boryczko B, Walczak M. Properties of new-generation hybrid layers combining hardfacing and nitriding dedicated to improvement in forging tools' durability. Arch Civ Mech Eng. 2020;20:78. https://doi. org/10.1007/s43452-020-00080-8.

9. Winnicki M, Małachowska A, Piwowarczyk T, Rutkowska-Gorczyca M, Ambroziak A. The bond strength of $\mathrm{Al}+\mathrm{Al}_{2} \mathrm{O}_{3}$ cermet coatings deposited by low-pressure cold spraying. Arch Civ Mech Eng. 2016;16:743-52. https://doi.org/10.1016/j.acme.2016.04. 014.

10. Łatka L, Michalak M, Szala M, Walczak M, Sokołowski P, Ambroziak A. Influence of $13 \mathrm{wt} \% \mathrm{TiO}_{2}$ content in alumina-titania powders on microstructure, sliding wear and cavitation erosion resistance of APS sprayed coatings. Surf Coat Technol. 2021;410: 126979. https://doi.org/10.1016/j.surfcoat.2021.126979.

11. Benedetti M, Torresani E, Leoni M, Fontanari V, Bandini M, Pederzolli C, Potrich C. The effect of post-sintering treatments on the fatigue and biological behavior of Ti-6Al-4V ELI parts made by selective laser melting. J Mech Behav Biomed Mater. 2017;71:295-306. https://doi.org/10.1016/j.jmbbm.2017.03.024.

12. Harun WSW, Manam NS, Kamariah MSIN, Sharif S, Zulkifly $\mathrm{AH}$, Ahmad I, Miura H. A review of powdered additive manufacturing techniques for Ti-6al-4v biomedical applications. Powder Technol. 2018;331:74-97. https://doi.org/10.1016/j.powtec.2018. 03.010.

13. de Peltz JS, Beltrami LVR, Kunst SR, Brandolt C, de Malfatti CF. Effect of the shot peening process on the corrosion and oxidation resistance of AISI430 stainless steel. Mater Res. 2015;18:538-45. https://doi.org/10.1590/1516-1439.316514.

14. Kameyama Y, Komotori J. Effect of micro ploughing during fine particle peening process on the microstructure of metallic materials. J Mater Process Technol. 2009;209:6146-55. https://doi.org/ 10.1016/j.jmatprotec.2009.08.010.

15. Trung PQ, Khun NW, Butler DL. Effects of shot peening pressure, media type and double shot peening on the microstructure, mechanical and tribological properties of low-alloy steel. Surf Topogr Metrol Prop. 2016;4:045001. https://doi.org/10.1088/ 2051-672X/4/4/045001.

16. Kovacı H, Bozkurt YB, Yetim AF, Aslan M, Çelik A. The effect of surface plastic deformation produced by shot peening on corrosion behavior of a low-alloy steel. Surf Coat Technol. 2019;360:78-86. https://doi.org/10.1016/j.surfcoat.2019.01.003.

17. Żebrowski R, Walczak M. Effect of the shot peening on surface properties and tribological performance of Ti-6Al-4V alloy produced by means of DMLS technology. Arch Metall Mater. 2019;64:377-83. https://doi.org/10.24425/amm.2019.126263.

18. Żebrowski R, Walczak M, Klepka T, Pasierbiewicz K. Effect of the shot peening on surface properties of Ti-6Al-4V alloy produced by means of DMLS technology. Eksploatacja i Niezawodnosc. 2019;21:46-53. https://doi.org/10.17531/ein.2019.1.6.

19. Żebrowski R, Walczak M, Korga A, Iwan M, Szala M. Effect of shot peening on the mechanical properties and cytotoxicity behaviour of titanium implants produced by 3D printing technology. J Healthc Eng. 2019. https://doi.org/10.1155/2019/8169538.

20. Dehghan-Manshadi A, Yu P, Dargusch M, StJohn D, Qian M. Metal injection moulding of surgical tools, biomaterials and medical devices: a review. Powder Technol. 2020;364:189-204. https:// doi.org/10.1016/j.powtec.2020.01.073.

21. Ganesh BKC, Sha W, Ramanaiah N, Krishnaiah A. Effect of shotpeening on sliding wear and tensile behavior of titanium implant alloys. Mater Des (1980-2015). 2014;56:480-6. https://doi.org/ 10.1016/j.matdes.2013.11.052.

22. Obata M, Sudo A (1993) Effect of shot peening on residual stress and stress corrosion cracking for cold worked austenitic stainless steel. In: Conf Proc: ICSP-5. pp 257-264

23. Dorr T, Hilpert M, Beckmerhagen P, Kiefer A, Wagner L (1999) Influence of shot peening on fatigue performance of high-strength 
aluminum-and magnesium alloys. In: Proceedings of the ICSP-7 Conference, Warsaw, Poland, pp 153-160

24. Ahmed AA, Mhaede M, Wollmann M, Wagner L. Effect of micro shot peening on the mechanical properties and corrosion behavior of two microstructure Ti-6Al-4V alloy. Appl Surf Sci. 2016;363:50-8. https://doi.org/10.1016/j.apsusc.2015.12.019.

25. Thijs L, Kempen K, Kruth J-P, Van Humbeeck J. Fine-structured aluminium products with controllable texture by selective laser melting of pre-alloyed AlSi10Mg powder. Acta Mater. 2013;61:1809-19. https://doi.org/10.1016/j.actamat.2012.11.052.

26. Yadroitsev I, Krakhmalev P, Yadroitsava I. Hierarchical design principles of selective laser melting for high quality metallic objects. Addit Manuf. 2015;7:45-56. https://doi.org/10.1016/j. addma.2014.12.007.

27. Matilainen V-P, Piili H, Salminen A, Nyrhilä O. Preliminary investigation of keyhole phenomena during single layer fabrication in laser additive manufacturing of stainless steel. Phys Procedia. 2015;78:377-87. https://doi.org/10.1016/j.phpro.2015.11. 052.

28. Solakoğlu EU, Gürgen S, Kuşhan MC. Surface topography of nickel-based superalloy manufactured with direct metal laser sintering (DMLS) method. Surf Topogr Metrol Prop. 2019;7:015012. https://doi.org/10.1088/2051-672X/aafe33.

29. Murr LE, Martinez E, Hernandez J, Collins S, Amato KN, Gay$\tan$ SM, Shindo PW. Microstructures and properties of 17-4 PH stainless steel fabricated by selective laser melting. J Market Res. 2012;1:167-77. https://doi.org/10.1016/S2238-7854(12)70029-7.

30. Cheruvathur S, Lass EA, Campbell CE. Additive manufacturing of 17-4 PH stainless steel: post-processing Heat treatment to achieve uniform reproducible microstructure. JOM. 2016;68:930 42. https://doi.org/10.1007/s11837-015-1754-4.

31. Dieter GE, Bacon D. Mechanical metallurgy. McGraw-Hill; 1988.

32. Jelliti S, Richard C, Retraint D, Roland T, Chemkhi M, Demangel C. Effect of surface nanocrystallization on the corrosion behavior of Ti-6Al-4V titanium alloy. Surf Coat Technol. 2013;224:82-7. https://doi.org/10.1016/j.surfcoat.2013.02.052.

33. Gahr K-HZ. Microstructure and wear of materials. Elsevier; 1987.

34. Gürgen S. Wear performance of UHMWPE based composites including nano-sized fumed silica. Compos B Eng. 2019;173: 106967. https://doi.org/10.1016/j.compositesb.2019.106967.

35. Gürgen S, Çelik ON, Kuşhan MC. Tribological behavior of UHMWPE matrix composites reinforced with PTFE particles and aramid fibers. Compos B Eng. 2019;173: 106949. https://doi.org/10. 1016/j.compositesb.2019.106949.

36. AlMangour B, Yang J-M. Improving the surface quality and mechanical properties by shot-peening of 17-4 stainless steel fabricated by additive manufacturing. Mater Des. 2016;110:914-24. https://doi.org/10.1016/j.matdes.2016.08.037.

37. Wang ZB, Tao NR, Li S, Wang W, Liu G, Lu J, Lu K. Effect of surface nanocrystallization on friction and wear properties in low carbon steel. Mater Sci Eng A. 2003;352:144-9. https://doi.org/ 10.1016/S0921-5093(02)00870-5.
38. Szala M, Łatka L, Walczak M, Winnicki M. Comparative study on the cavitation erosion and sliding wear of cold-sprayed $\mathrm{Al} /$ $\mathrm{Al}_{2} \mathrm{O}_{3}$ and $\mathrm{Cu} / \mathrm{Al}_{2} \mathrm{O}_{3}$ coatings, and stainless steel aluminium alloy, copper and brass. Metals. 2020;10:856. https://doi.org/10.3390/ met10070856.

39. Lashgari HR, Li S, Kong C, Asnavandi M, Zangeneh Sh. Rotary friction welding of additively manufactured 17-4PH stainless steel. J Manuf Process. 2021;64:1517-28. https://doi.org/10. 1016/j.jmapro.2021.03.008.

40. Yang Y, Zhu Y, Khonsari MM, Yang H. Wear anisotropy of selective laser melted 316L stainless steel. Wear. 2019;428-429:37686. https://doi.org/10.1016/j.wear.2019.04.001.

41. Kc S, Nezhadfar PD, Phillips C, Kennedy MS, Shamsaei N, Jackson RL. Tribological behavior of 17-4 PH stainless steel fabricated by traditional manufacturing and laser-based additive manufacturing methods. Wear. 2019;440-441: 203100. https:// doi.org/10.1016/j.wear.2019.203100.

42. Ameer MA, Khamis E, Al-Motlaq M. Electrochemical behaviour of recasting $\mathrm{Ni}-\mathrm{Cr}$ and $\mathrm{Co}-\mathrm{Cr}$ non-precious dental alloys. Corros Sci. 2004;46:2825-36. https://doi.org/10.1016/j.corsci.2004.03. 011.

43. Walczak M, Drozd K. Effects of recasting of CoCrMoW dental alloy on its microstructure and corrosion resistance. Curr Issues Pharm Med Sci. 2013;36:425-9. https://doi.org/10.12923/j.2084980X/26.4/a.17.

44. Song D, Ma AB, Jiang JH, Lin PH, Yang DH, Fan JF. Corrosion behaviour of bulk ultra-fine grained AZ91D magnesium alloy fabricated by equal-channel angular pressing. Corros Sci. 2011;53:362-73. https://doi.org/10.1016/j.corsci.2010.09.044.

45. Wu S, Wang S, Wang G, Yu X, Liu W, Chang Z, Wen D. Microstructure, mechanical and corrosion properties of magnesium alloy bone plate treated by high-energy shot peening. Trans Nonferr Metals Soc China. 2019;29:1641-52. https://doi.org/10.1016/ S1003-6326(19)65071-5.

46. Aung NN, Zhou W. Effect of grain size and twins on corrosion behaviour of AZ31B magnesium alloy. Corros Sci. 2010;52:589_ 94. https://doi.org/10.1016/j.corsci.2009.10.018.

47. Opt-Hoog C, Birbilis N, Estrin Y. Corrosion of pure Mg as a function of grain size and processing route. Adv Eng Mater. 2008;10:579-82. https://doi.org/10.1002/adem.200800046.

48. Qiao M, Hu J, Guo K, Wang Q. Influence of shot peening on corrosion behavior of low alloy steel. Mater Res Express. 2020;7: 016574. https://doi.org/10.1088/2053-1591/ab6920.

Publisher's Note Springer Nature remains neutral with regard to jurisdictional claims in published maps and institutional affiliations. 